Final Report

\title{
Reduction of Glass Surface Reflectance by Ion Beam Surface Modification
}

\author{
Contract DE-EE0000590 \\ Mark Spitzer \\ Photonic Glass Corporation \\ 661 Pleasant Street \\ Norwood, MA 02062
}

March 11, 2009

This contract was funded by the American Re-Investment and Recovery Act of 2009. 


\section{EXECUTIVE SUMMARY}

This is the final report for DOE contract DE-EE0000590. The purpose of this work is to determine the feasibility of the reduction of the reflection from the front of solar photovoltaic modules. Reflection accounts for a power loss of approximately $4 \%$. A solar module having an area of one square meter with an energy conversion efficiency of $18 \%$ generates approximately 180 watts. If reflection loss can be eliminated, the power output can be increased to 187 watts. Since conventional thin-film antireflection coatings do not have sufficient environmental stability, we investigated the feasibility of ion beam modification of the glass surface to obtain reduction of reflectance. Our findings are generally applicable to all solar modules that use glass encapsulation, as well as commercial float glass used in windows and other applications.

Ion implantation of argon, fluorine, and xenon into commercial low-iron soda lime float glass, standard float glass, and borosilicate glass was studied by implantation, annealing, and measurement of reflectance. The three ions all affected reflectance. The most significant change was obtained by argon implantation into both low-iron and standard soda-lime glass. In this way samples were formed with reflectance lower than can be obtained with a single-layer coatings of magnesium fluoride. Integrated reflectance was reduced from $4 \%$ to $1 \%$ in low-iron soda lime glass typical of the glass used in solar modules. The reduction of reflectance of borosilicate glass was not as large, but borosilicate glass is not typically used in flat plate solar modules.

Unlike conventional semiconductor ion implantation doping, glass reflectance reduction was found to be tolerant to large variations in implant dose, meaning that the process does not require high dopant uniformity. Additionally, glass implantation does not require mass analysis. Simple, high current ion implantation equipment can be developed for this process; however, before the process can be employed on full scale solar modules, equipment must be developed for ion implanting large sheets of glass. A cost analysis shows that the process can be economical. Our finding is that the reduction of reflectance by ion beam surface modification is technically and economically feasible. The public will benefit directly from this work by the improvement of photovoltaic module efficiency, and indirectly by the greater understanding of the modification of glass surfaces by ion beams. 


\subsection{INTRODUCTION}

Uncoated, non-texturized low-iron float glass of the type used in flat plate solar modules has a reflectance of approximately 4\%. A similar reflection loss also occurs on the front surface of Fresnel-based concentrator modules. The reduction or elimination of this reflectance from module front surfaces at the system level offers an improvement in efficiency independent of the underlying solar cell technology, and has been the subject of research on glass anti-reflection (AR) coatings, ${ }^{(1)}$ grooved coverglass, ${ }^{(2)}$ and textured glass $^{(3)}$ (see also ref. 4 for other examples). Most of this power loss can be recaptured if the AR coating or surface treatment is environmentally stable and does not increase soiling of the module. Although the use of thin-film $\mathrm{MgF}_{2}$ is well known as a glass $\mathrm{AR}$ coating, ${ }^{(5)}$ thin films of $\mathrm{MgF}_{2}$ are generally not sufficiently rugged for outdoor applications. Additionally, the use of a single-layer AR coating on glass does not provide the full benefit that is obtainable from broad-band multi-layer AR coatings. Moreover, concentrator systems have additional glass-air interfaces that would benefit from low-loss surfaces. However, multi-layer coatings are expensive unless they are encapsulated, they are sensitive to environmental factors. In order to reduce or eliminate reflective loss, we need a low-cost process that provides the benefits of a multi-layer AR coating, but without environmental vulnerability.

This work investigated the feasibility ion implantation to modify the surface of glass to reduce the index of refraction and in this way reduce reflectance. The ion implantation method comprises the ionization of an elemental material, acceleration of a stream of ions by an electrostatic field, ion mass selection using a static magnetic field, and a final stage of acceleration using a second electrostatic field. The accelerated ions thus produced are of known mass and energy. The ion impinges upon a target material and is embedded within the surface, at a depth that depends on ion energy and the composition of the target material. By implanting ions, the composition of the nearsurface region of the target may be modified.

Ion implantation is currently the dopant method of choice in the semiconductor industry owing to the high degree of automation, process control, and uniformity. Ion implantation is also a clean process. Its application to glass surface modification preserves these benefits: the process is carried out in vacuum, is dry, produces no effluent, and the glass needs no significant post-implant processing.

The basis for this work was a report by Chinellato et al in 1982 on surface modification of low-iron soda-lime glass using $\mathrm{Ar}^{+}$ion implantation. ${ }^{(6)}$ In this key early paper, the authors implanted $\mathrm{Ar}^{+}$at $50 \mathrm{keV}$ and at doses of $10^{16} \mathrm{~cm}^{-2}, 3 \times 10^{16} \mathrm{~cm}^{-2}$ and $10^{17} \mathrm{~cm}^{-2}$, and observed a change of up to $25 \%$ in reflectance at $590 \mathrm{~nm}$. Measured reflectance of $4.2 \%$ was reduced to less than $3 \%$. Profiling of $\mathrm{Na}$ concentration indicated that the change in index of refraction near the surface correlates with $\mathrm{Na}$ depletion. The authors also reported that lower dose implants $\left(3 \times 10^{16} \mathrm{~cm}^{-2}\right)$ improve the mechanical properties of the glass.

Deshkovskaya $^{(7)}$ has studied the mechanisms in changes to index of refraction owing to ion implantation and has proposed that the implanted ions change the bonding within the glass and hence change the frequency-dependent polarizability of the bonds. While the work was not conclusive as to the physical mechanism, the experimental data 
supported the general finding that ion implantation can change the reflectance of glass surfaces. The approach was also supported by Polato et al who provide further evidence that the index change in ion implanted glass is related to a $\mathrm{Na}$ depletion layer. ${ }^{(8)}$ The depletion is greatest at the surface and zero at a depth $\mathrm{d}$, and graded between. It is presumed that the grading of $\mathrm{Na}$ ion concentration that leads to a graded-index profile. As we will show in this report, we replicated this early work and we showed that the mechanism is not $\mathrm{Na}$ depletion, and does not lead directly to formation of graded structures.

Our approach involved ion implantation of a range of glass substrates, including low iron soda-lime glass commonly used in flat plate modules, borosilicate glass used in some concentrator optics, and fused silica which has been considered for use in secondary optical elements. We also examined various ions including Ar, Xe and F, to examine the importance of compositional changes, and to find species that could be implanted with high beam current.

The importance of high beam current cannot be overstated. Previous work ${ }^{(6-8)}$ used $\mu \mathrm{A}$ beam current which is too low for any economical use of ion implantation. For example, modification of surfaces require typical implant dose of about $5 \times 10^{16}$ ions $/ \mathrm{cm}^{2}$ $\left(8 \times 10^{-3} \mathrm{C} / \mathrm{cm}^{2}\right)$. Thus, to implant one square centimeter in one second, we require a beam current of $8 \mathrm{~mA}$ which is in the range of today's medium current ion implanters. The work that we will report on considered whether reduction of surface index of refraction could be attained at these currents, and whether such current would be economical. The process results will be discussed in Section 2, and the cost factors will be discussed in section 5 .

\subsection{PROCESS DEVELOPMENT}

The objective of this task was to create a baseline ion implantation process and measure the sensitivity to implant conditions. Most of the work in this task was focused on implantation into low iron soda-lime glass and borosilicate glass. All samples were 5 $\mathrm{cm} \times 5 \mathrm{~cm} \times 3 \mathrm{~mm}$ and were polished on both sides. Low iron soda-lime glass (Trade name "Optiwhite," from Pilkington) was used as a proxy for standard solar module glass. We also used a borosilicate glass (Trade name "Borofloat," from Schott) as a proxy for various borosilicates that are used in concentrator optics. We will use the trade names in the discussion to follow to simplify identification of the glass. A small amount of fused silica from Corning was also used in the $\mathrm{F}$ experiments.

Early work ${ }^{(6)}$ on implantation in glass focused on $\mathrm{Ne}$, $\mathrm{Ar}$ and $\mathrm{Kr}$, with best results obtained with Ar. Therefore our baseline comprised Ar. We also were interested in whether high atomic mass would yield better results. Since early reports showed that $\mathrm{Kr}$ did not produce better results than Ar, we selected Xe for additional study. The literature $^{(6-8)}$ also suggested that $\mathrm{Na}$ depletion was the cause of the decrease in index of refraction, therefore, we evaluated ion implantation of $F$ to examine whether we could cause compositional changes in the glass that would reduce the dielectric constant.

In order to develop processes for modifying the index of refraction, it is necessary to understand the effects of changes in energy and dose of the ion implant process. Energy primarily controls the average depth of the ions, and dose controls the peak concentration. The distribution of implanted ions can be modeled using calculations of 
projected range. The position of the ions can also be affected by annealing of the target after or during the implantation. Annealing often has a beneficial effect of restoring bonds that may have been disrupted during the implant. In crystalline materials, annealing restores the lattice. The role of annealing in glass is not well understood. Owing to the importance of energy and dose, it was important to conduct a careful study of the effects of each, as well as the effects of annealing. Additionally, for glass it is necessary to determine whether beam current has an effect on reflectance.

\subsection{Baseline Argon Implantation}

Experiments to form a baseline Ar implantation process began with ion implantation of $\mathrm{Ar}$ at $50 \mathrm{keV}$ into five Optiwhite glass wafers. After implantation, reflectance was measured using a PV Measurements reflectance spectrometer calibrated with reflectance standards from Avian Technology. Results are shown in Fig. 1 for five doses. Note that we are measuring reflectance from both sides of the glass sample, but we are implanting only one side. It can be seen in the figure that the reflectance of each sample was reduced to compared to the non-implanted control. The lowest reflectance was attained with a dose of $3 \times 10^{16} / \mathrm{cm}^{2}$.

We also examined the importance of energy by repeating this experiment at 22.5 , $75 \mathrm{keV}$, and $105 \mathrm{keV}$. The results are shown in Figures 2-4. As the implantation energy is increased, the Ar is implanted deeper. The consequence is that that layer becomes more reflecting than untreated glass. This is similar to making an AR coating too thick.

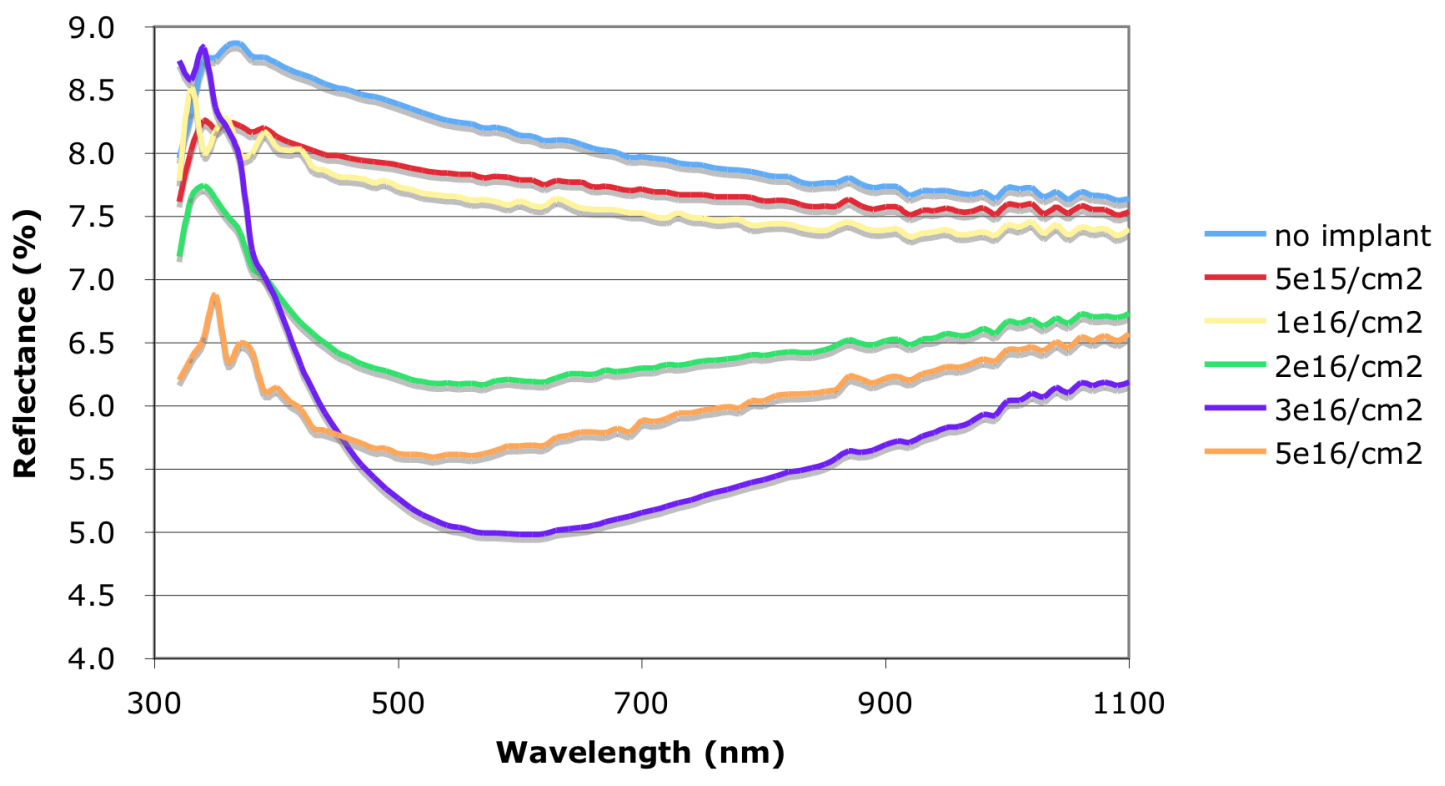

Figure 1. Reflectance of low-Fe soda-lime glass implanted with Ar at $50 \mathrm{keV}$. 
FINAL REPORT

CONTRACT DE-EE0000590

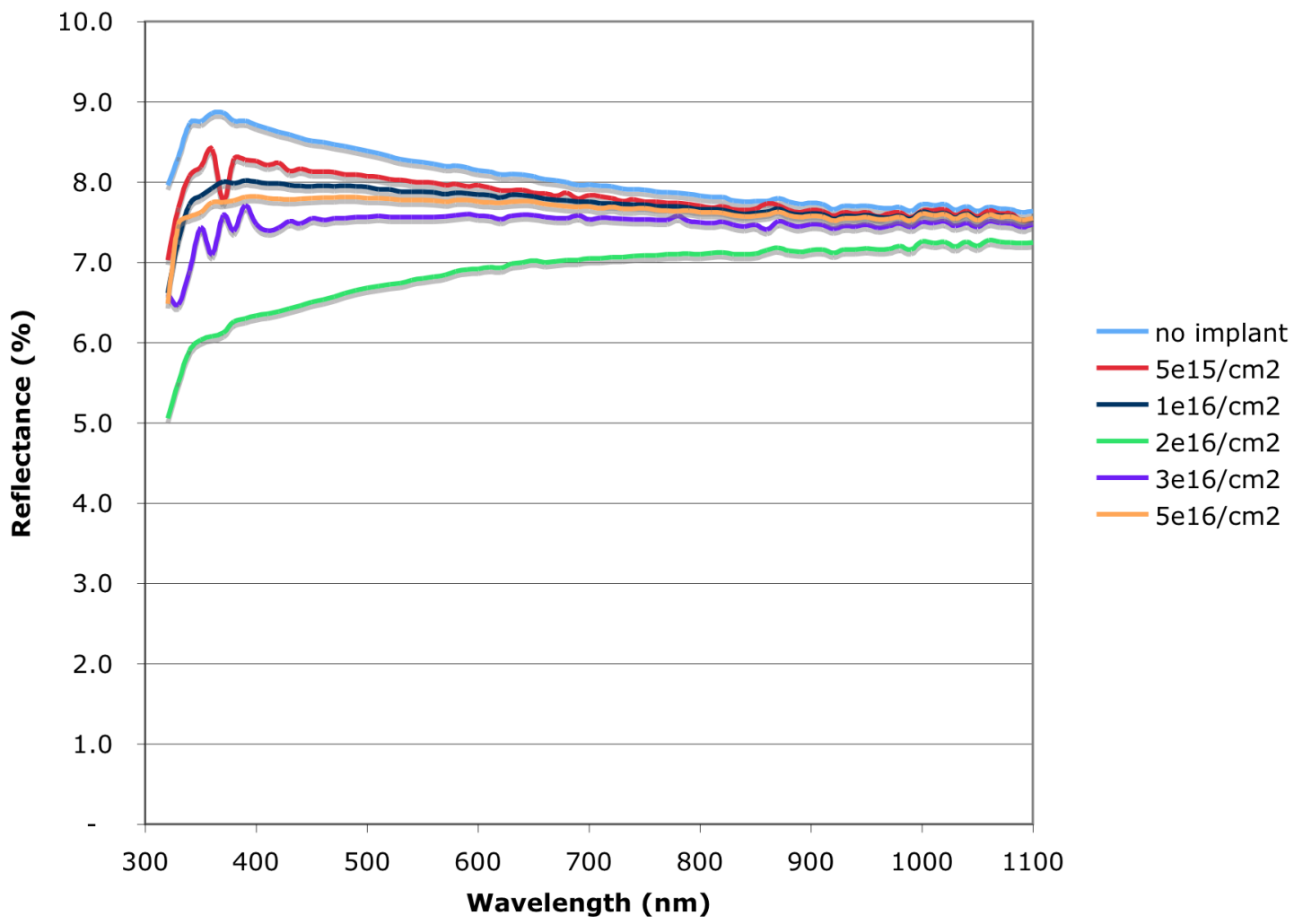

Figure 2. Ar Implantation into Optiwhite at $22.5 \mathrm{keV}$.

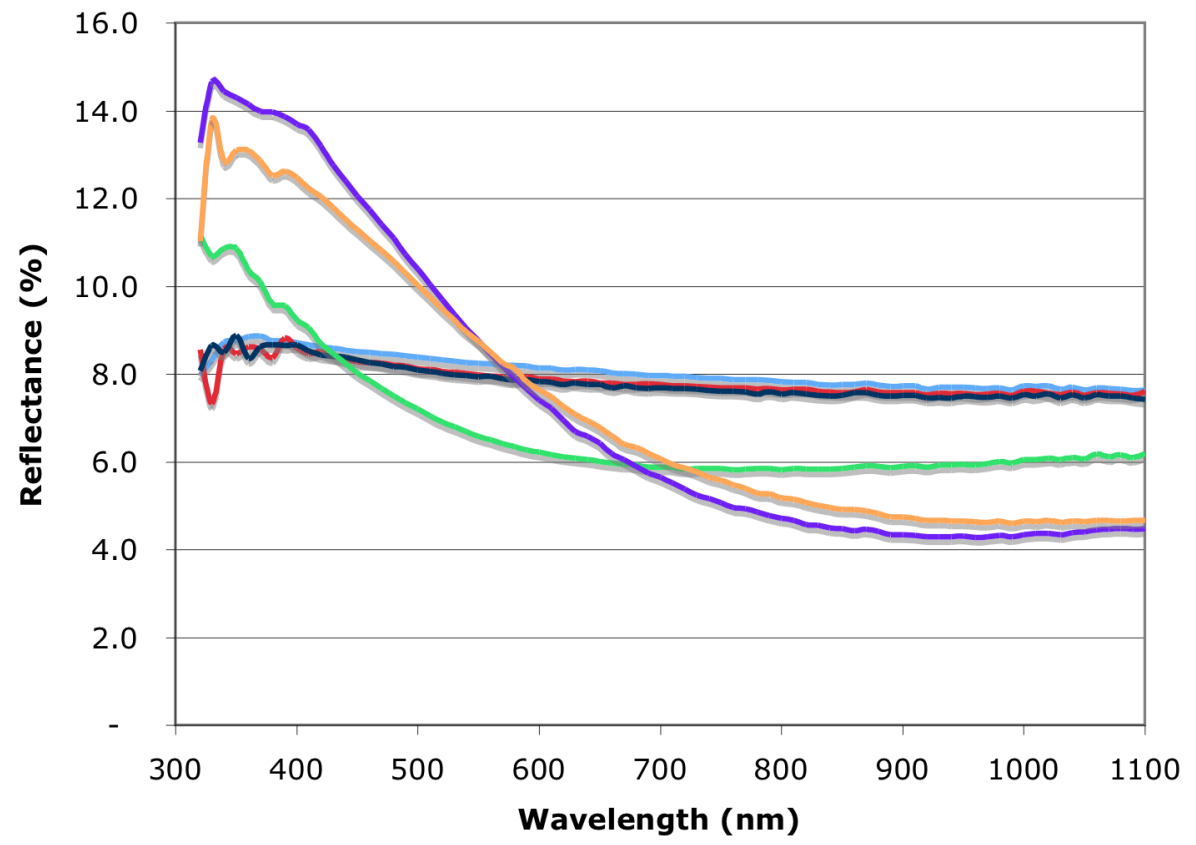

- no implant

5.00E+15

$-1.00 \mathrm{E}+16$

$2.00 \mathrm{E}+16$

$3.00 \mathrm{E}+16$

$5 \mathrm{e} 16 / \mathrm{cm} 2$

Figure 3. Ar implantation into Optiwhite glass at $75 \mathrm{keV}$. 




Figure 4. Ar implantation into Optiwhite glass at $105 \mathrm{keV}$.

Ar implantation into Borofloat glass was conducted in parallel with the Optiwhite study. Figures 5 to 8 show the reflectance at each implant energy and dose. The Borofloat did not respond significantly to the Ar implant. There is an effect at $50 \mathrm{keV}$, but it is small. 
FINAL REPORT

CONTRACT DE-EE0000590

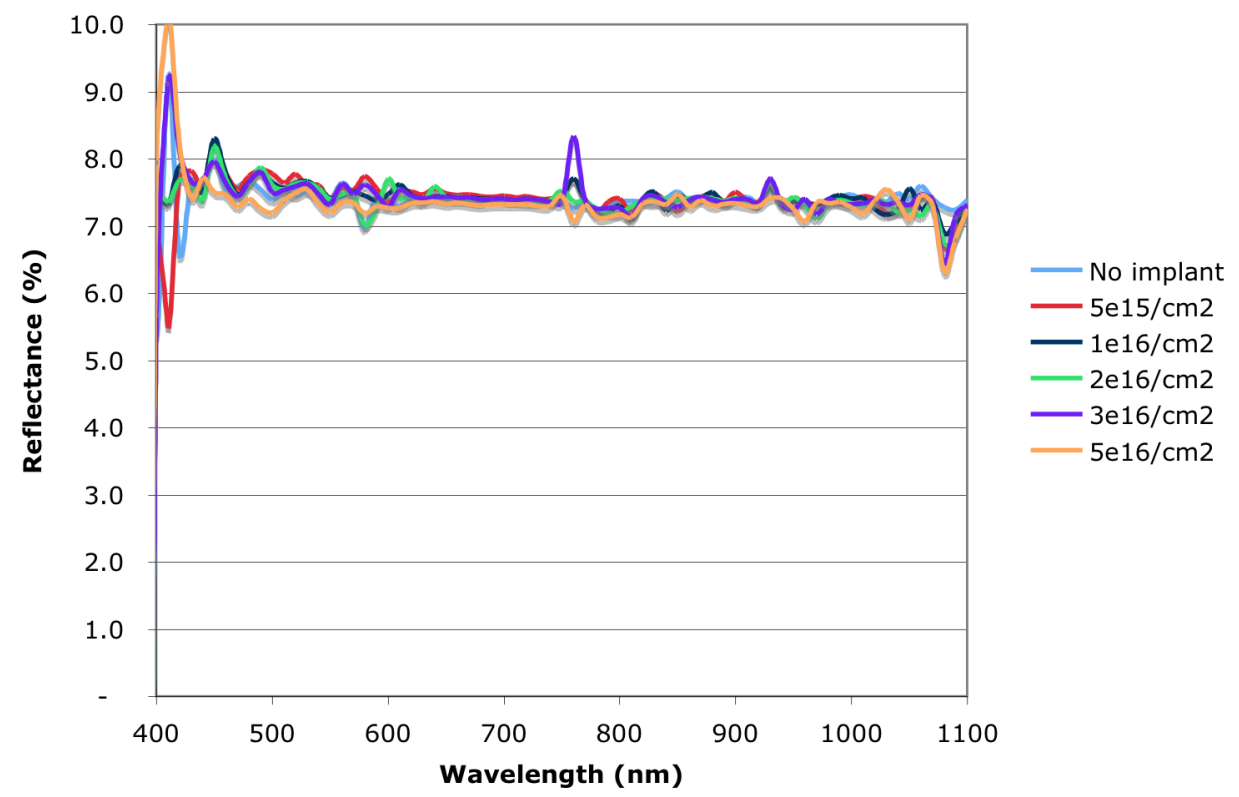

Figure 5. Ar implantation into Borofloat at $22.5 \mathrm{keV}$.

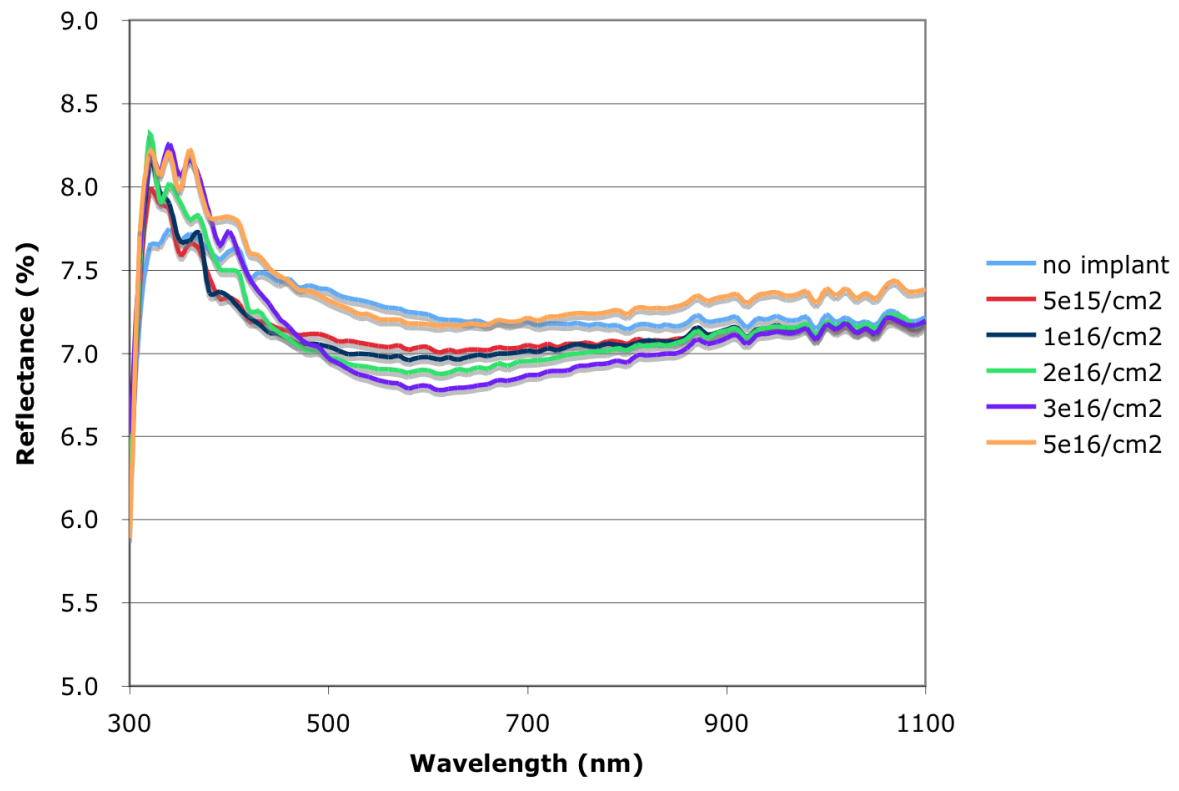

Figure 6. Ar implantation into Borofloat glass at $50 \mathrm{keV}$. 


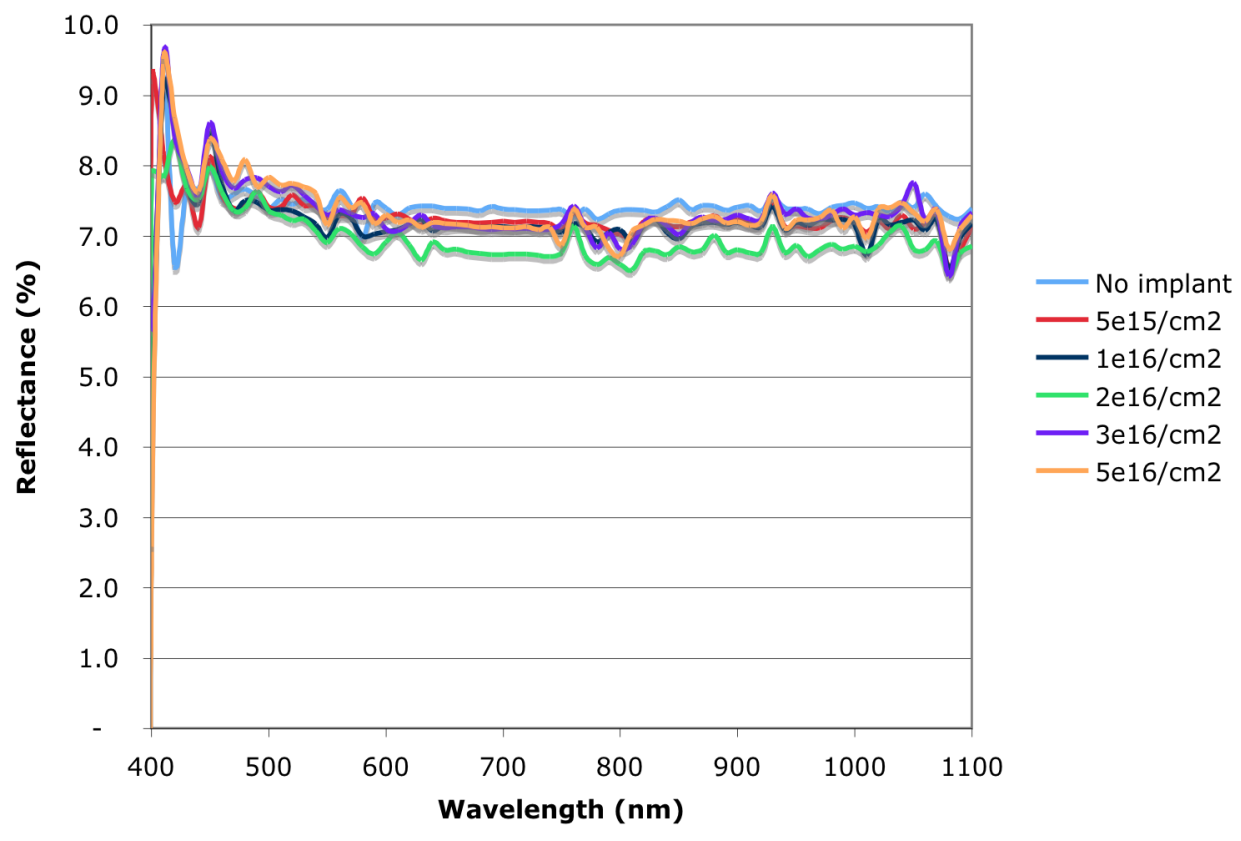

Figure 7. Ar implantation into Borofloat at $75 \mathrm{keV}$.

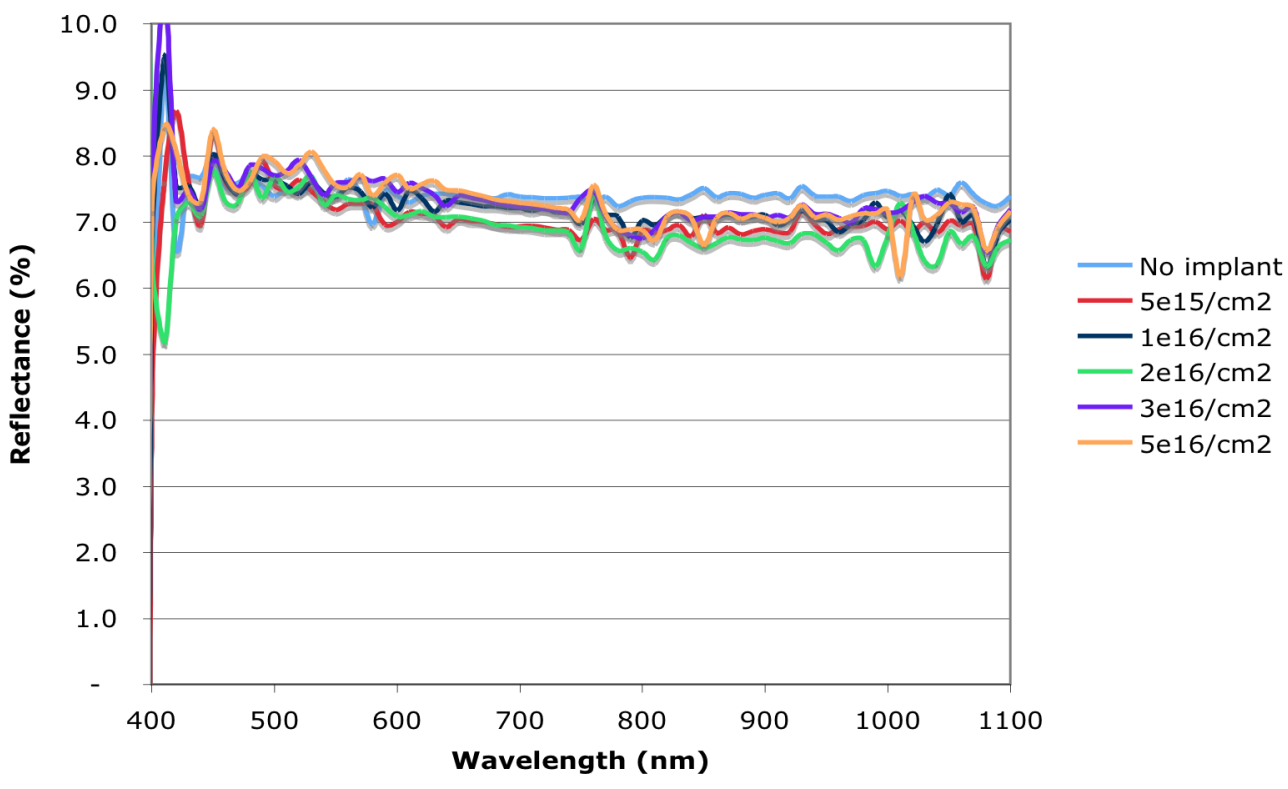

Figure 8. Ar implantation into Borofloat at $105 \mathrm{keV}$. 


\subsection{Implanter Current and Anneal Study}

Owing to the importance of implanter current, we examined whether there is a dependence of reflectance on implant current. In this experiment the implant conditions comprised $\mathrm{Ar}^{+}$at $50 \mathrm{keV}, 1 \times 10^{17} \mathrm{~cm}^{-2}$. Two beam currents were used: $1 \mathrm{~mA}$ and $2.5 \mathrm{~mA}$. We also examined the effects of an anneal in flowing $\mathrm{N}_{2}$.

\subsubsection{Low-Fe Soda Lime Glass (Optiwhite)}

Fig. 9 shows the reflectance of untreated Optiwhite glass. Also show in the figure is the reflectance after annealing at $300 \mathrm{C}$ for $30 \mathrm{~min}$. The anneal causes a small increases in reflectance. At $600 \mathrm{~nm}$ he reflectance increases from $8 \%$ to $8.4 \%$. The same sample was subjected to a second anneal at $500 \mathrm{C}$ for $30 \mathrm{~min}$. and the reflectance is not changed further, as is evident in Fig. 9.

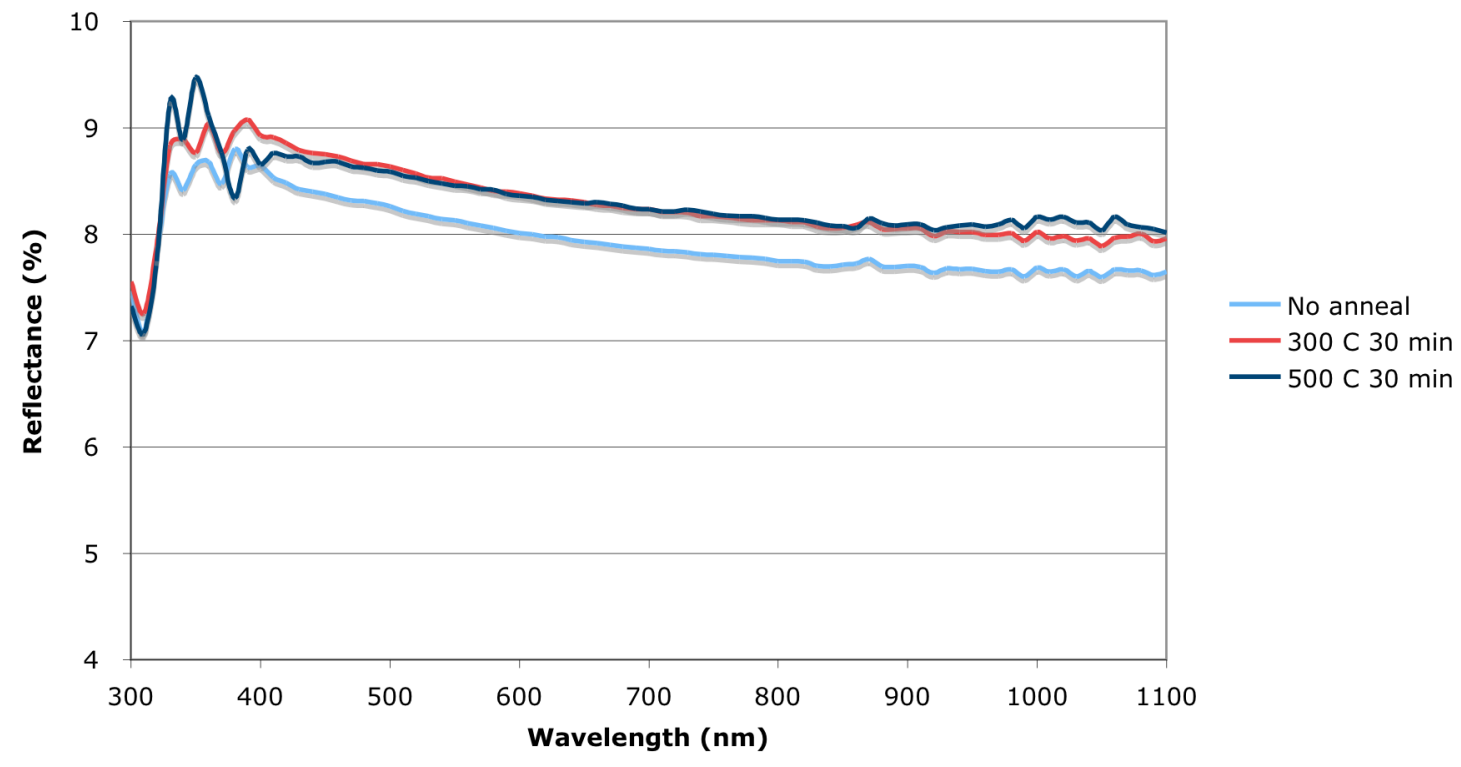

Figure 9. Reflectance of low-Fe soda lime "Optiwhite" glass before and after annealing at $300 \mathrm{C}$ and $500 \mathrm{C}$.

Fig. 10 shows the reflectance of Optiwhite glass implanted with Ar at $50 \mathrm{keV}$, $1 \times 10^{17} \mathrm{~cm}^{-2}$, using a beam current of $1 \mathrm{~mA}$, before and after annealing. As in the case of the control glass (Fig. 9) there is an increase in reflectance resulting from the anneal. Fig. 11 shows the effect of the anneal for the sample implanted with a beam current of 2.5 $\mathrm{mA}$. The results are substantially the same. From this we conclude that the annealing effect is largely independent of implant. 


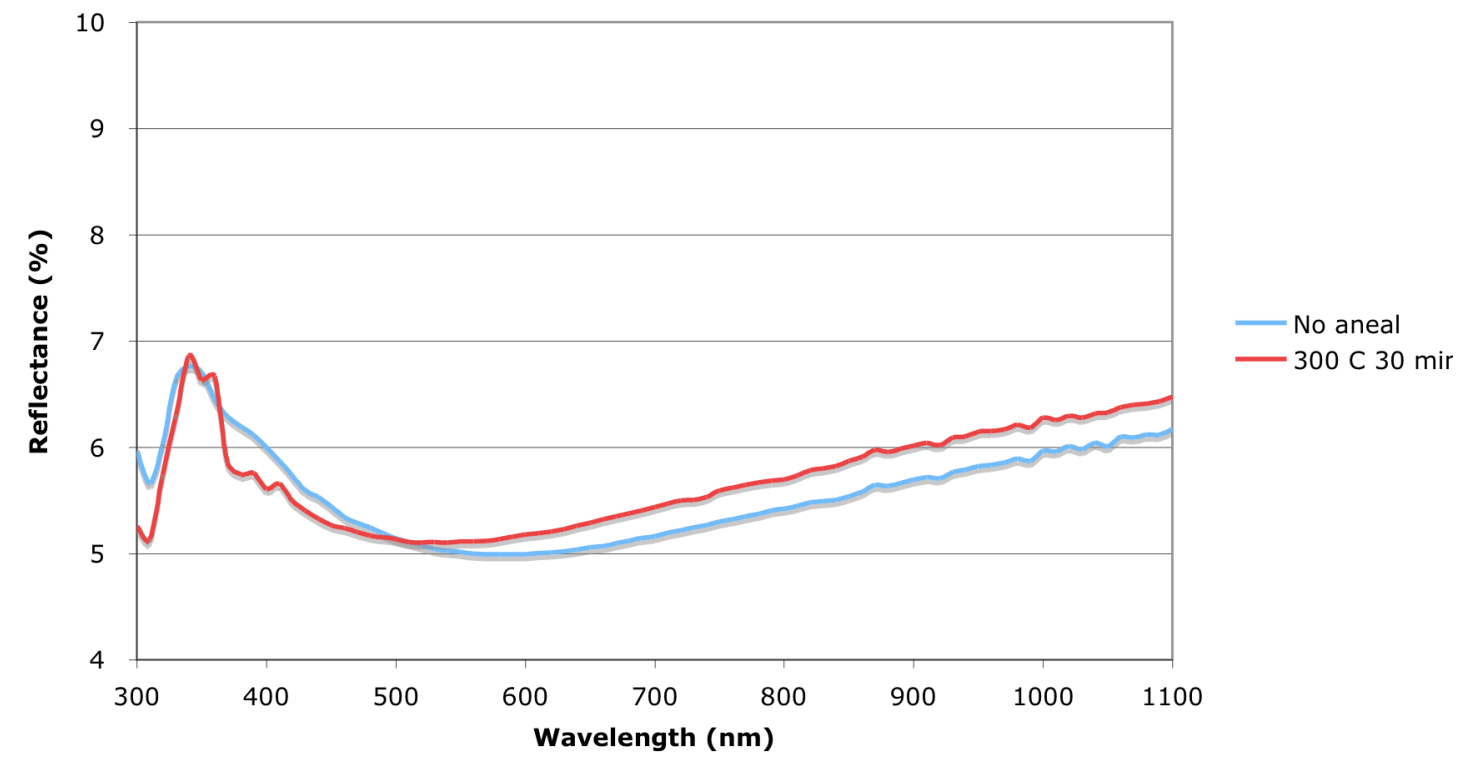

Figure 10. Reflectance of Optiwhite glass implanted with Ar at $50 \mathrm{keV}$, with beam current of $1 \mathrm{~mA}$ before and after annealing at $300 \mathrm{C}$. The dose is $1 \times 10^{17} / \mathrm{cm}^{2}$.

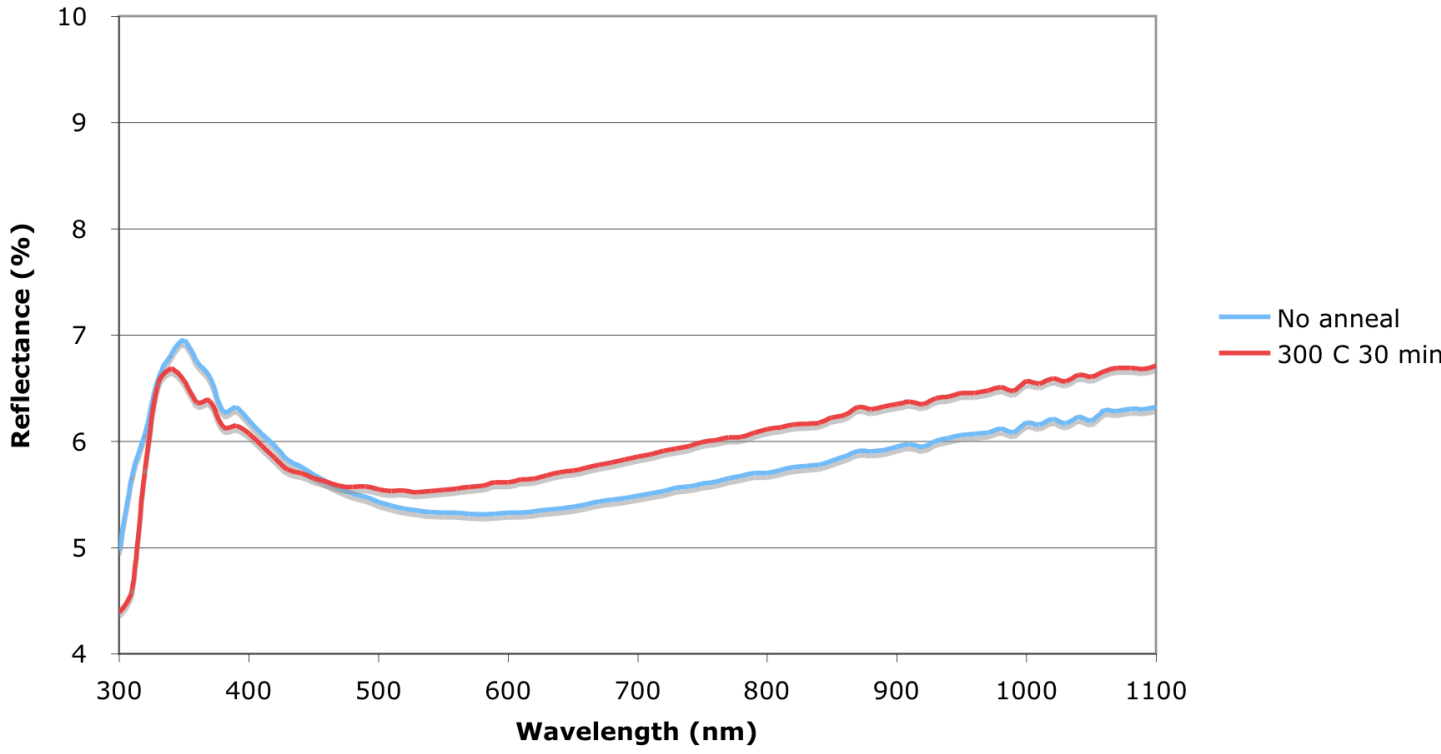

Figure 11. Reflectance of Optiwhite glass implanted with Ar at $50 \mathrm{keV}$ with beam current of $2.5 \mathrm{~mA}$ before and after annealing at $300 \mathrm{C}$. The dose is $1 \times 10^{17} / \mathrm{cm}^{2}$.

Fig. 12 shows a comparison of the reflectance of the samples prior to annealing, and Fig. 13 shows the reflectance after annealing. The lower current produced a lower reflectance. The reason for this difference has not yet been identified, but it is possible that the higher current may have raised the temperature of the sample more than the lower current, leading to a small amount of annealing. The higher current might also 
FINAL REPORT

CONTRACT DE-EE0000590

have increased the charging of the sample, leading to a lower dose. Either effect, if present would act to increase reflectance.

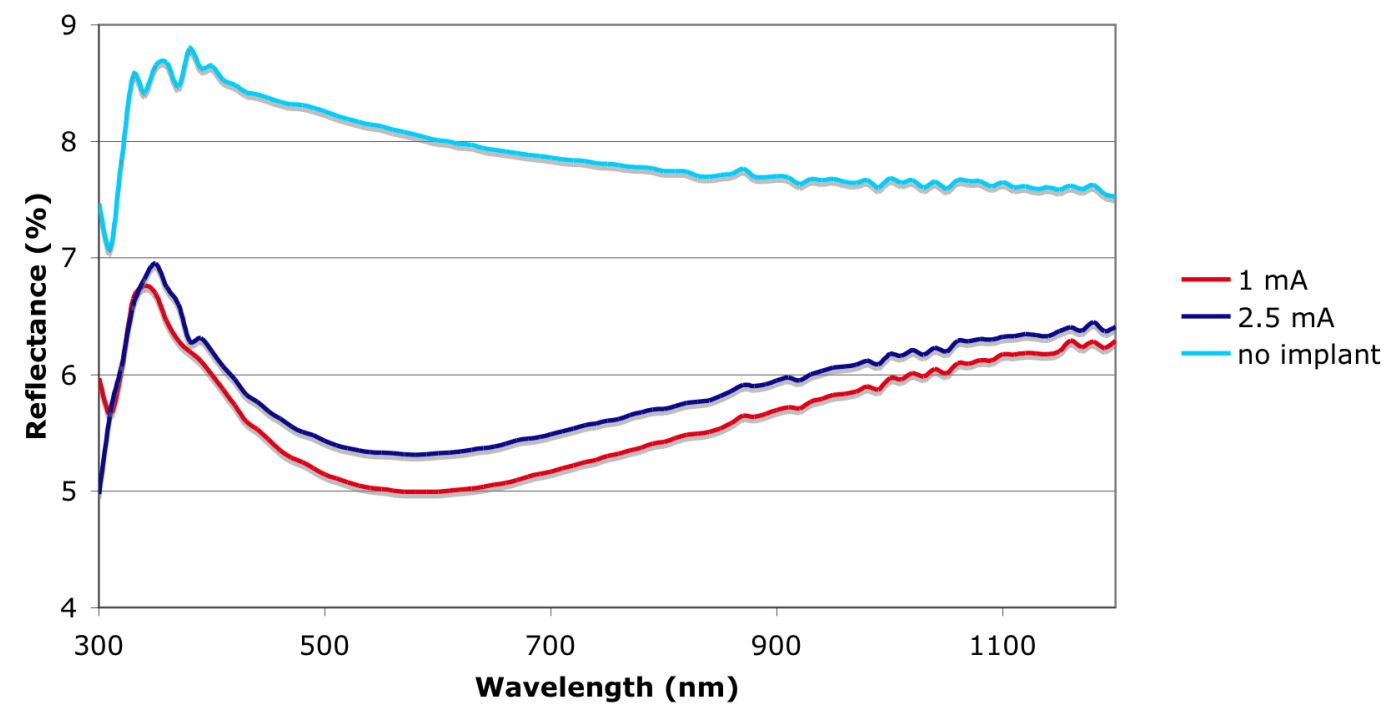

Figure 12. Comparison of reflectance for two implant currents, prior to annealing.

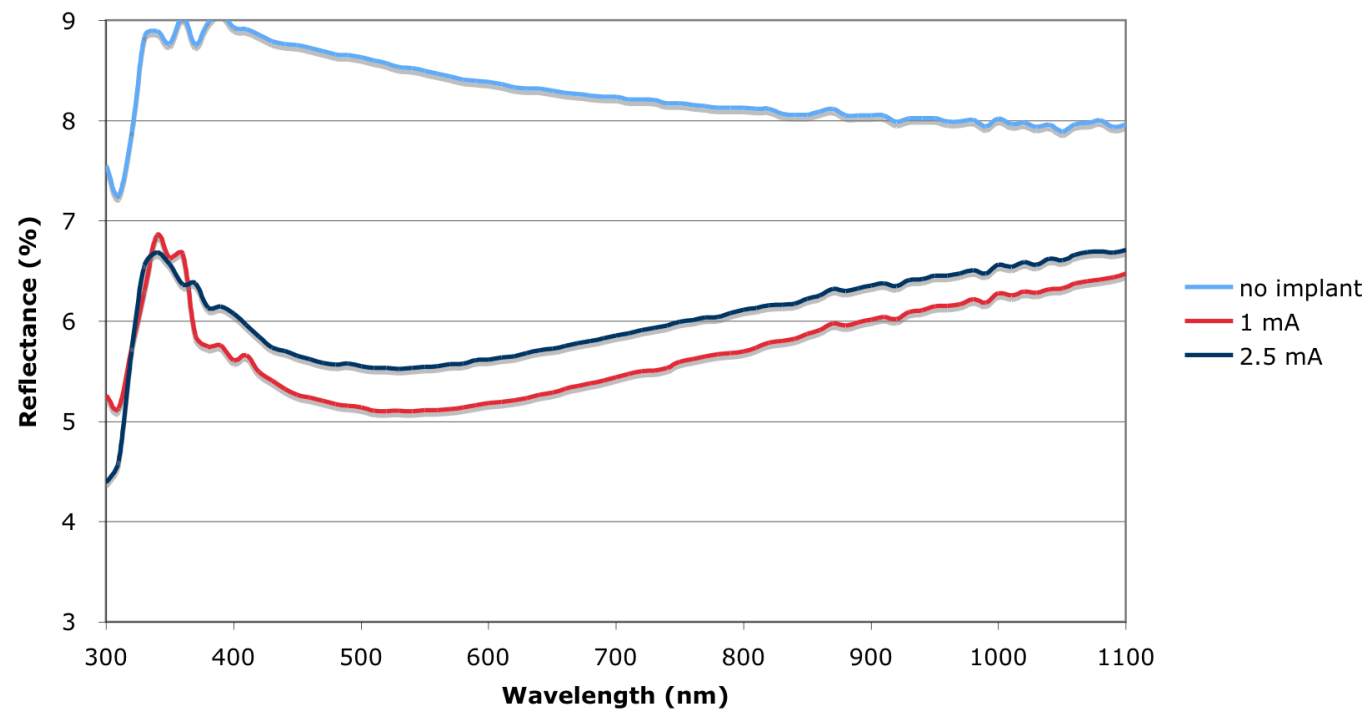

Figure 13. Comparison of reflectance for two implant currents, after annealing at $300 \mathrm{C}$ for $30 \mathrm{~min}$. 
FINAL REPORT

CONTRACT DE-EE0000590

\subsubsection{Implant Current Study in Borofloat}

Fig. 14 shows the reflectance of Borofloat glass before and after anneal. Unlike Optiwhite, the Borofloat shows a small decrease in reflectance from annealing. Fig. 1517 show the reflectance of Borofloat glass implanted with Ar at $50 \mathrm{keV}, 1 \times 10^{17} / \mathrm{cm}^{2}$, with no anneal, $300 \mathrm{C}$ for $30 \mathrm{~min}$, and $500 \mathrm{C}$ for $30 \mathrm{~min}$. The implants have relatively little effect, and the current seems to have only a small effect. The anneals make little difference.

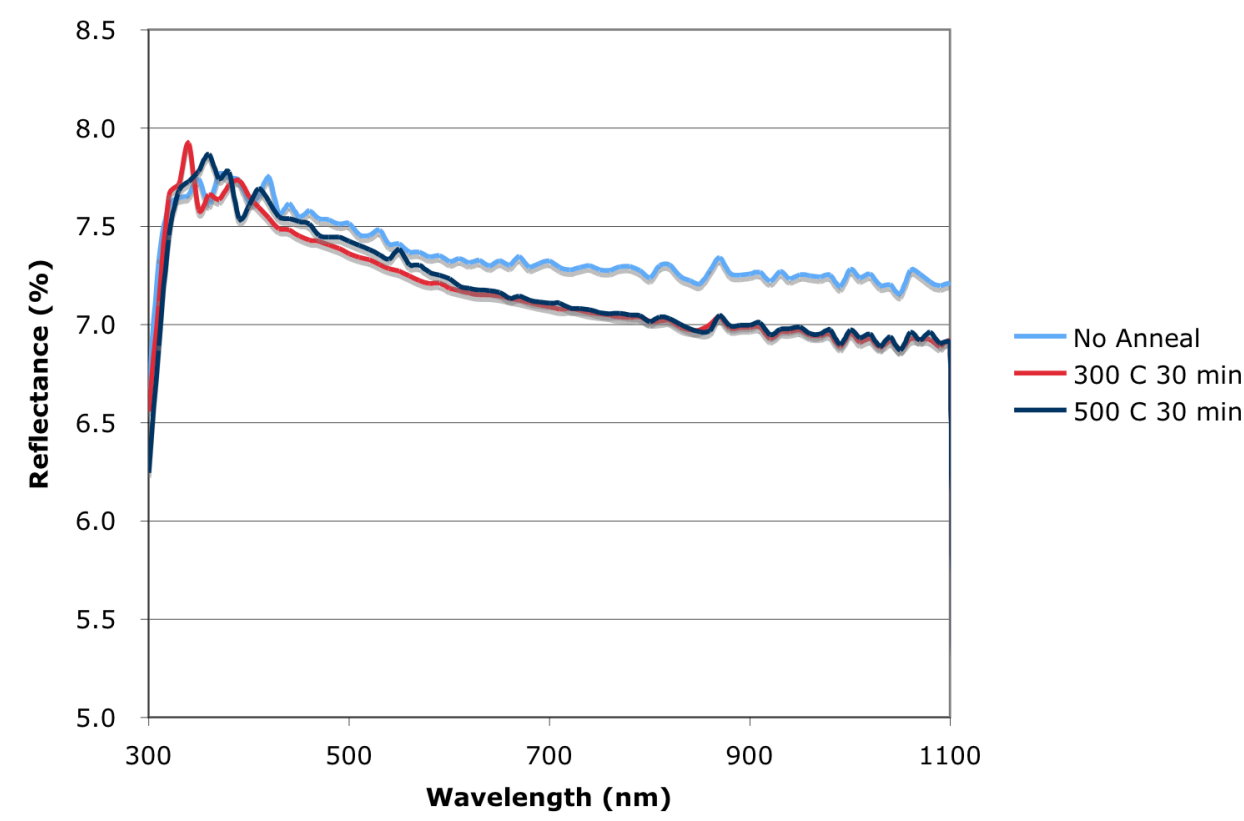

Figure 14. Reflectance of Borofloat glass before and after anneal (no implant).

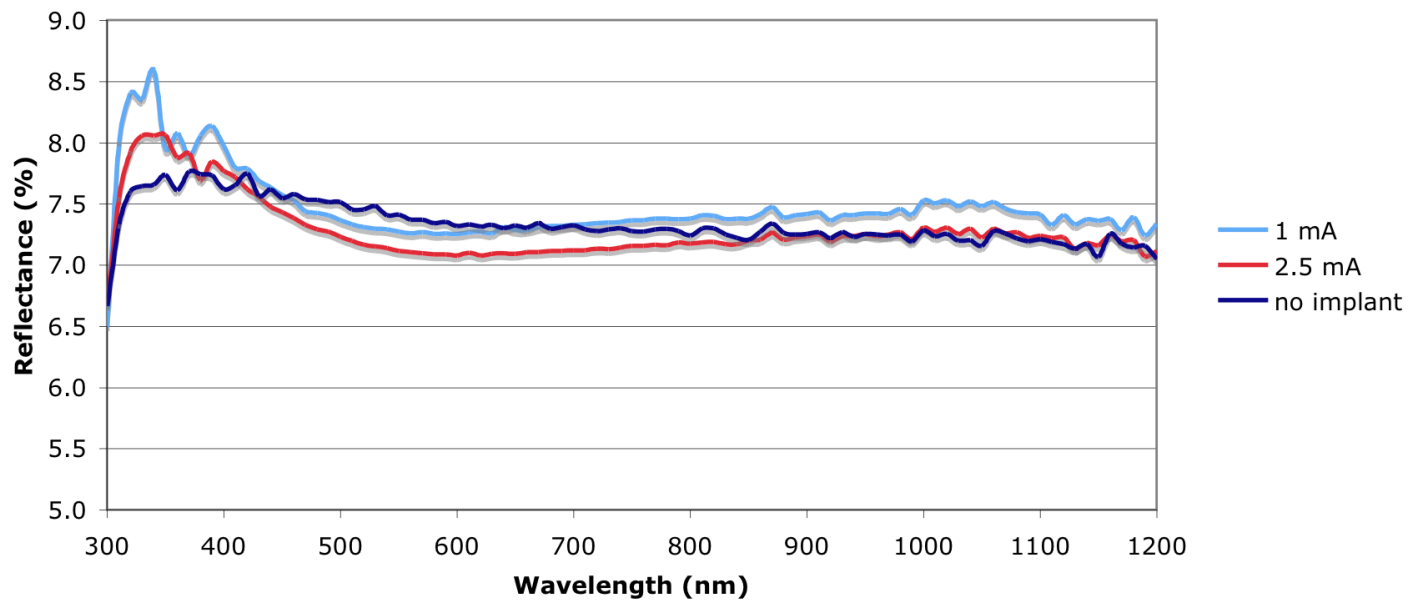

Figure 15. Ar implanted at $50 \mathrm{keV}$ into Borofloat glass. Dose is $1 \times 10^{17} / \mathrm{cm}^{2}$. 


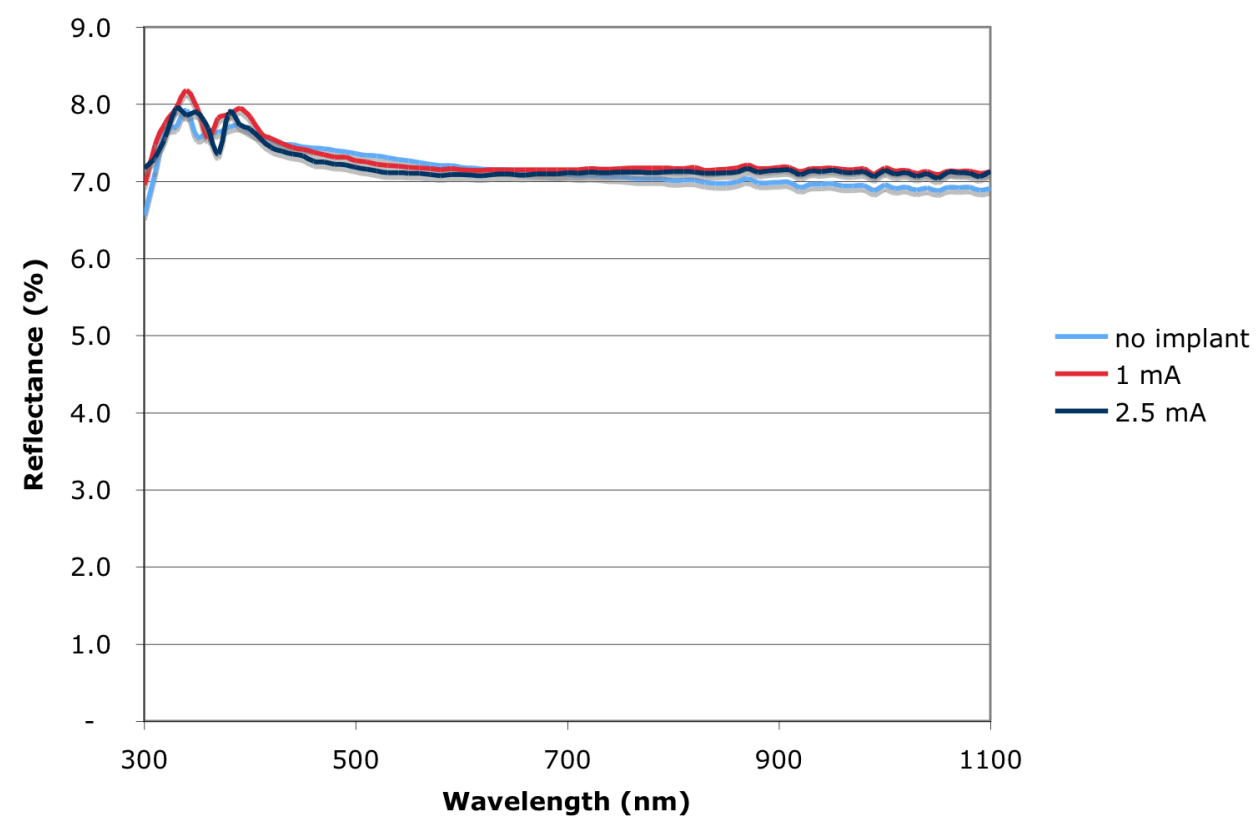

Figure 16. Reflectance of Borofloat glass after $50 \mathrm{keV}$ Ar implant, $1 \times 10^{17} / \mathrm{cm}^{2}$, and an anneal at $300 \mathrm{C}$ for $30 \mathrm{~min}$.

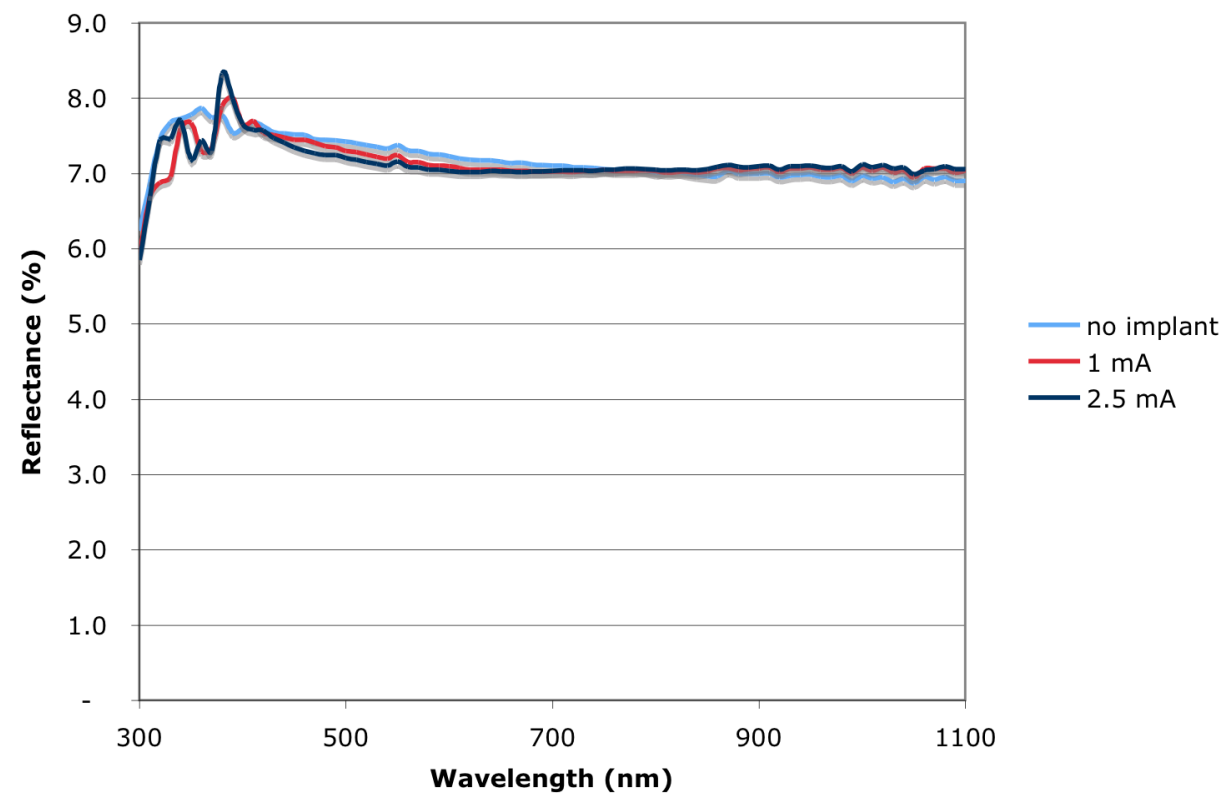

Figure 17. Reflectance of Borofloat glass after $50 \mathrm{keV} \mathrm{Ar} \mathrm{implant,} 1 \times 10^{17} / \mathrm{cm}^{2}$, and an anneal at $500 \mathrm{C}$ for $30 \mathrm{~min}$. 


\subsection{OPTICAL TESTING AND MODELING}

\subsection{Comparison to Magnesium Fluoride}

The reflectance data in the previous section is based on measurements of reflectance from the front and back of the glass. Since the reflectance of the unimplanted side is known, the total reflectance data can be corrected to obtain the reflectance of the implanted surface. In this section, our modeling is based on singlesided reflectance, and we will correct the measured reflectance data to compare measured and modeled single sided reflectance.

An important question is how well our implanted surfaces correspond to the lowest reflectance that can be attained with an antireflection (AR) coating. Typical AR coatings on glass use magnesium fluoride $\left(\mathrm{MgF}_{2}\right)$. We have used the known index of refraction as a function of wavelength of $\mathrm{MgF}_{2}$ to calculate best case reflectance, using Essential Macleod thin film modeling software. We have also purchased commercial glass coated with $\mathrm{MgF}_{2}$ to obtain a measurement of the commercial state of the art.

Fig. 18 shows a comparison of uncoated glass to the commercial $\mathrm{MgF}_{2}$ coating and to the Ar-implanted surface. The ion implanted layer $\left(\mathrm{Ar}, 50 \mathrm{keV}, 3 \times 10^{16} / \mathrm{cm}^{2}\right)$ is clearly superior. Figure 19 compares the reflectance of the ion implanted layer to the ideal $\mathrm{MgF}_{2}$ layer. The implanted layer is slightly better than the ideal $\mathrm{MgF}_{2}$ layer. This indicates to us that the implanted layer is optically very similar to a single layer AR coating.

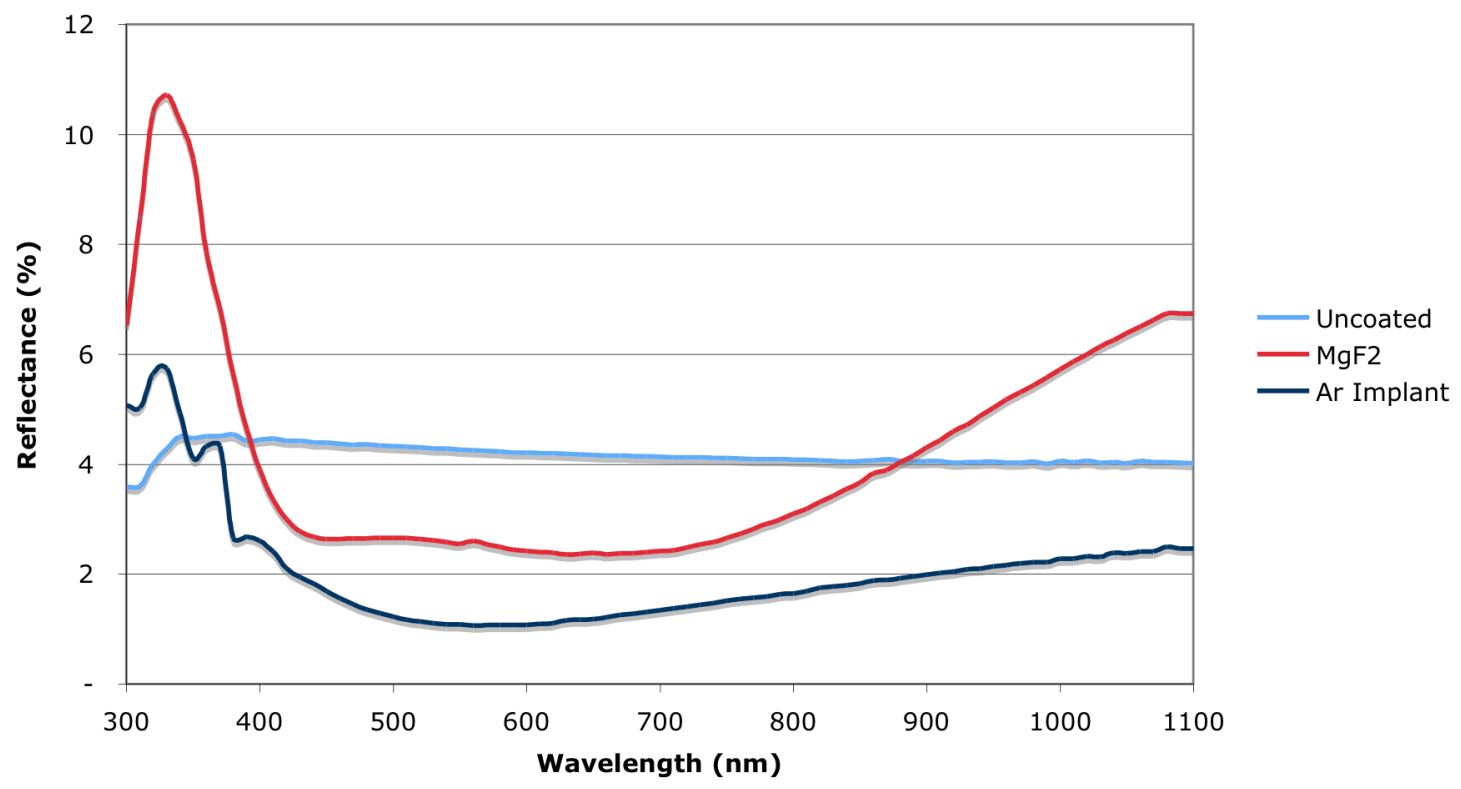

Figure 18. Comparison of commercial $\mathrm{MgF}_{2}$ coating to Ar implantation for reflectance reduction. The ion implanted layer is superior to the $\mathrm{MgF}_{2}$ layer. 


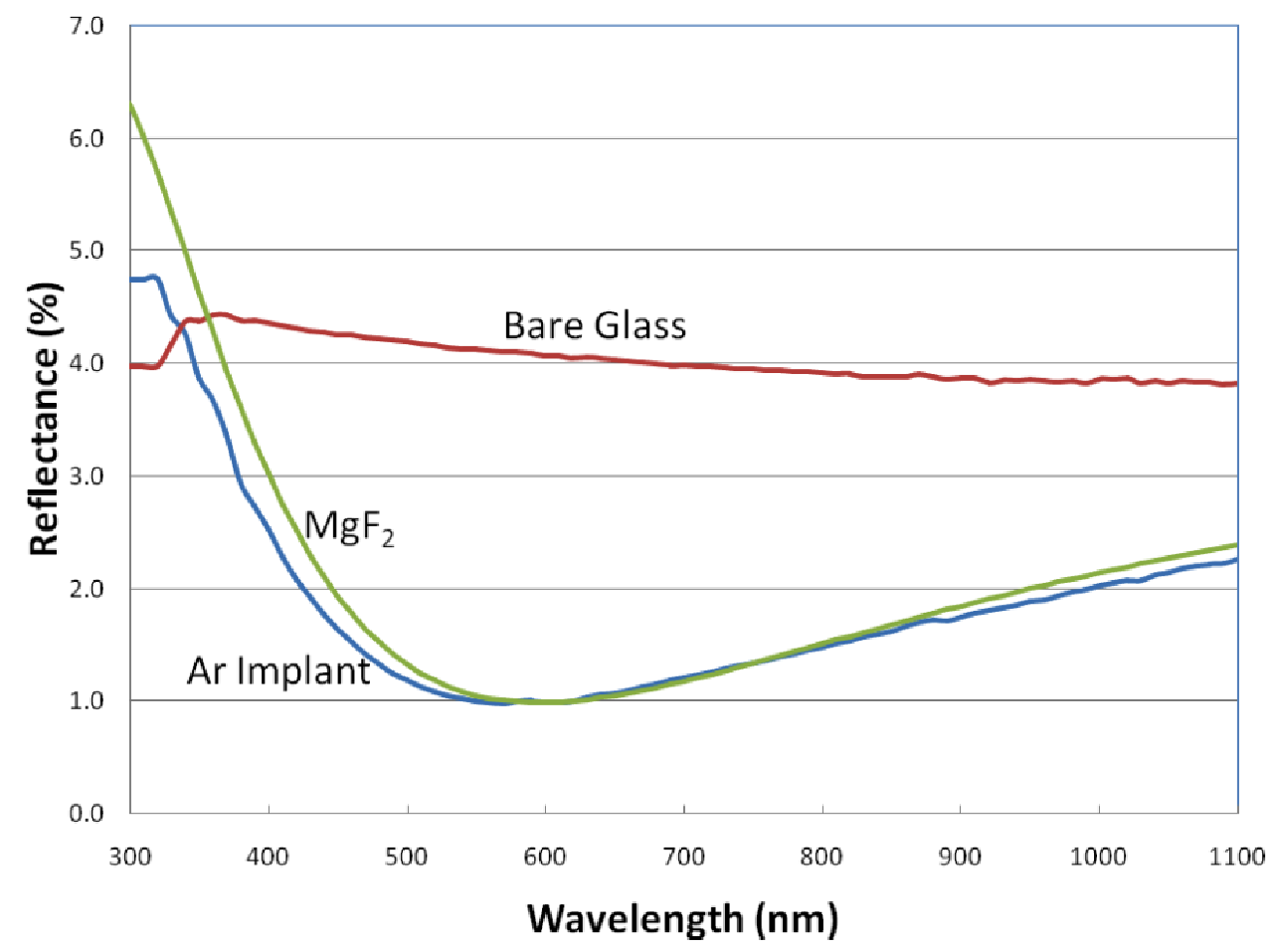

Figure 19. Single-side reflectance of Ar-implanted layer compared to a calculation of optimized $\mathrm{MgF}_{2}$ on soda lime glass.

\subsection{Compositional Analysis}

One proposed explanation for the change in surface index of refraction in soda lime glass is the rearrangement of the $\mathrm{Na}$ caused by the Ar ion bombardment. We have verified that the $\mathrm{Na}$ concentration has been modified by obtaining secondary ion mass spectroscopy (SIMS) analysis (Evans Analytical Lab) on two samples of implanted Optiwhite glass. Fig. 20 shows the analysis of the sample implanted with Ar at $50 \mathrm{keV}$ and $3 \times 10^{16} \mathrm{~cm}^{-2}$, and Fig. 21 shows the same dose implanted at $105 \mathrm{keV}$. The rearrangement of the Na shown by SIMS is consistent with findings in the literature of the 1980's; however, we believe that the change in Na depth profile is not adequate to explain the change in index of refraction. We have used a model proposed by Fantone ${ }^{(9)}$ to estimate the index of refraction as a function of composition, and to determine the change occurring from $\mathrm{Na}$ depletion. Using Fantone's method, we find that even if the $\mathrm{Na}$ were to be removed from the glass completely, it would not change the index of refraction sufficiently to explain our results. 


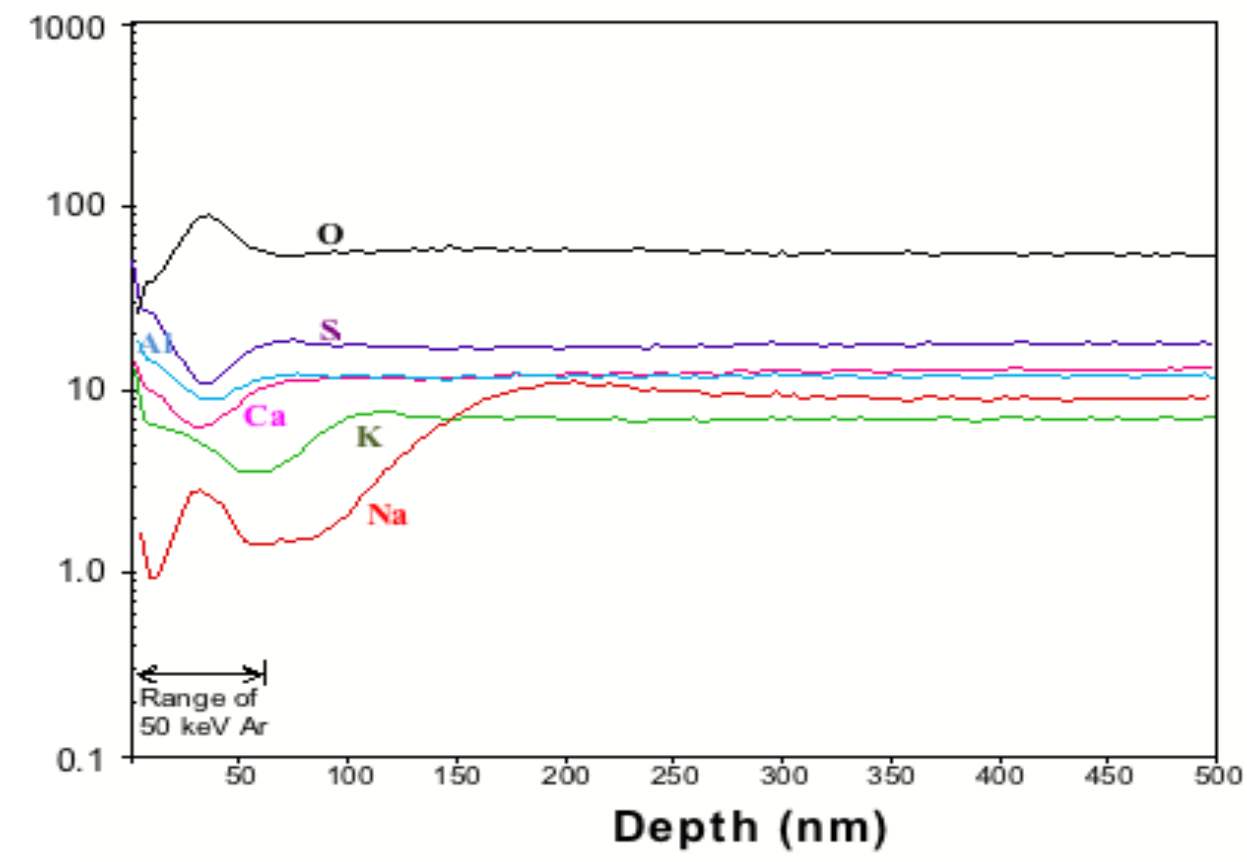

Figure 20. SIMS of Optiwhite glass implanted with Ar at $50 \mathrm{keV}, 3 \times 10^{16} \mathrm{~cm}^{-2}$. The Na is depleted in the first $100 \mathrm{~nm}$ of glass.

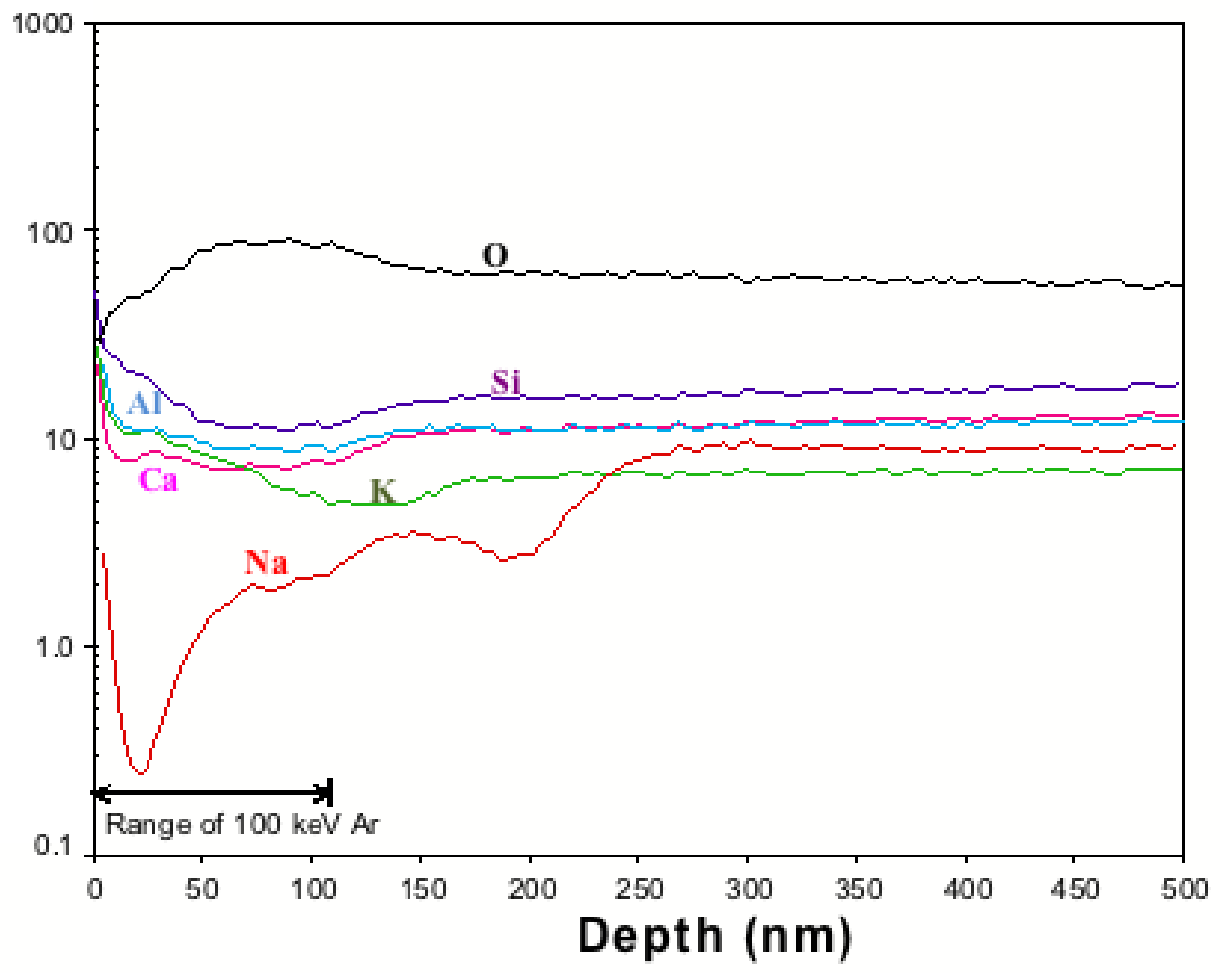

Figure 20. SIMS of Optiwhite glass implanted with Ar at $105 \mathrm{keV}, 3 \times 10^{16} \mathrm{~cm}^{-2}$. The $\mathrm{Na}$ is depleted in the first $200 \mathrm{~nm}$ of glass. 


\subsection{Mechanism for Reduction of Index of Refraction}

Compositional changes are not sufficient to explain the results we observe. Microanalysis using cross sectional TEM of the Ar-implanted region shows that the Ar forms a matrix of micro-voids beneath the surface of soda lime glass. We presume that the voids are formed by knock-on collisions, and that the voids are either filled with Ar (forming a micro-bubble), or the Ar eventually diffuses out of the implanted region leaving the voids. This is consistent with the SIMS data that show rearrangement of the atoms in the glass matrix. The resulting voids or bubbles reduce the dielectric constant of the glass. We were not able to determine why the borosilicate glass does not support as much micro-void formation, but the most simple explanation is that the mechanical strength of the borosilicate glass is higher, and that this strength prevents collisions with Ar from displacing atoms in the glass matrix.

Other noble ions probably change the index of refraction by similar mechanisms. Whether this the mechanism of micro-void formation causes $F$ to change the index of refraction was not determined. 


\subsection{APPLICABILITY}

Baseline results with Borofloat and Optiwhite glass show that the process is applicable to flat plate modules, almost all of which are made with low-Fe soda lime glass. Concentrator systems may use borosilicate glass for cell covers, secondary optical elements, and for external support of an acrylic Fresnel lens. Application to concentrators requires development of a process for alternative glass. Alternative ions are one approach to concentrator applications.

\subsection{Fluorine Implantation}

Fluorine was implanted at $20 \mathrm{keV}$ into Optiwhite glass and the resultant reflectance was measured before and after annealing. Fig. 22 shows the reflectance of Optiwhite glass that was implanted with $\mathrm{F}^{+}$at $20 \mathrm{keV}$ at three doses. F causes a reduction in the reflectance in the UV and blue, but the IR reflectance is unchanged. In contrast, Fig. 23 shows reflectance data obtained from $\mathrm{F}^{+}$implanted Borofloat glass. The Borofloat shows a greater reduction in reflectance. Figures 24 and 25 show the reflectance of similar samples implanted at $40 \mathrm{keV}$. Clearly, the deeper dose is changing the refractive index in a wider and deeper level, and consequently, the lowest reflectance is moved toward the IR.

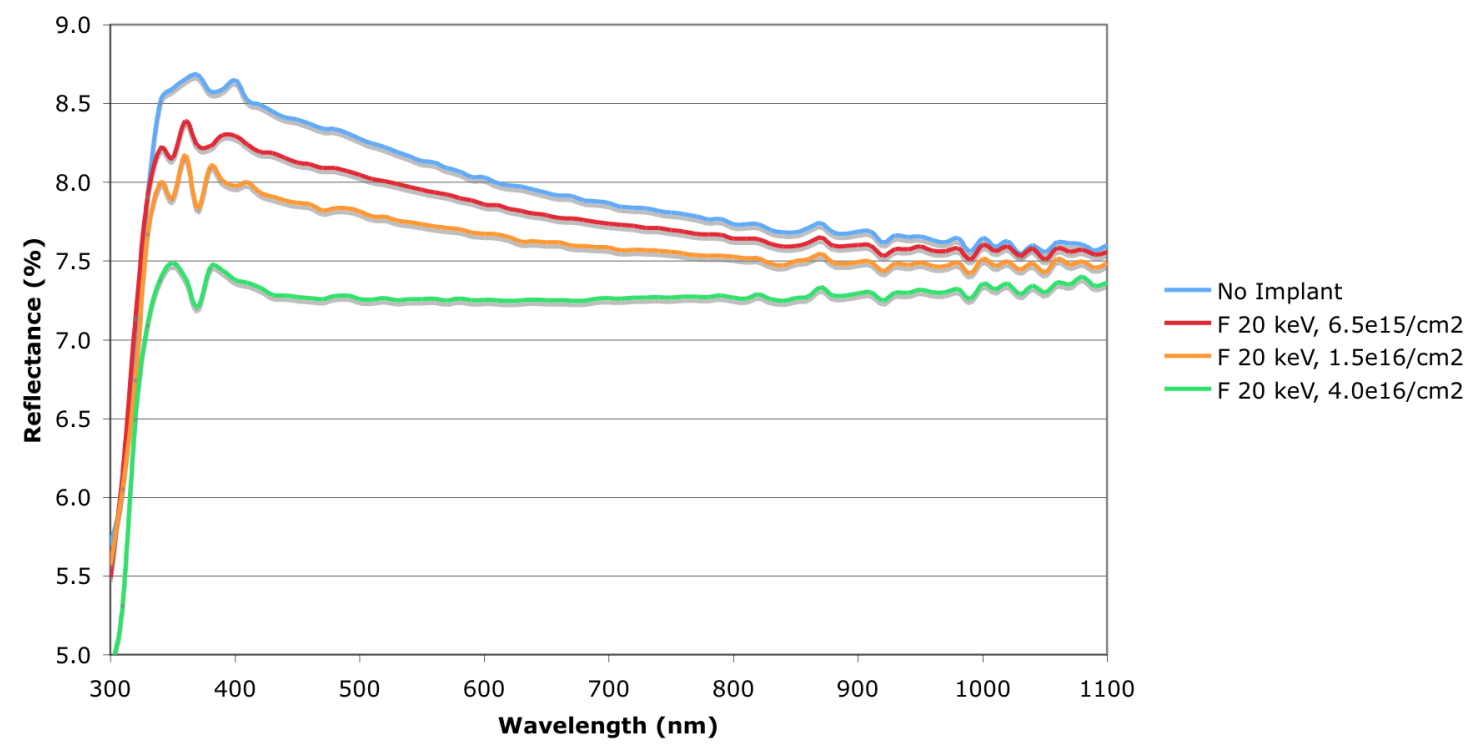

Figure 22. Optiwhite glass implanted with $\mathbf{F}^{+}$at $20 \mathrm{keV}$ at three doses. Also shown is untreated glass. 
FINAL REPORT

CONTRACT DE-EE0000590

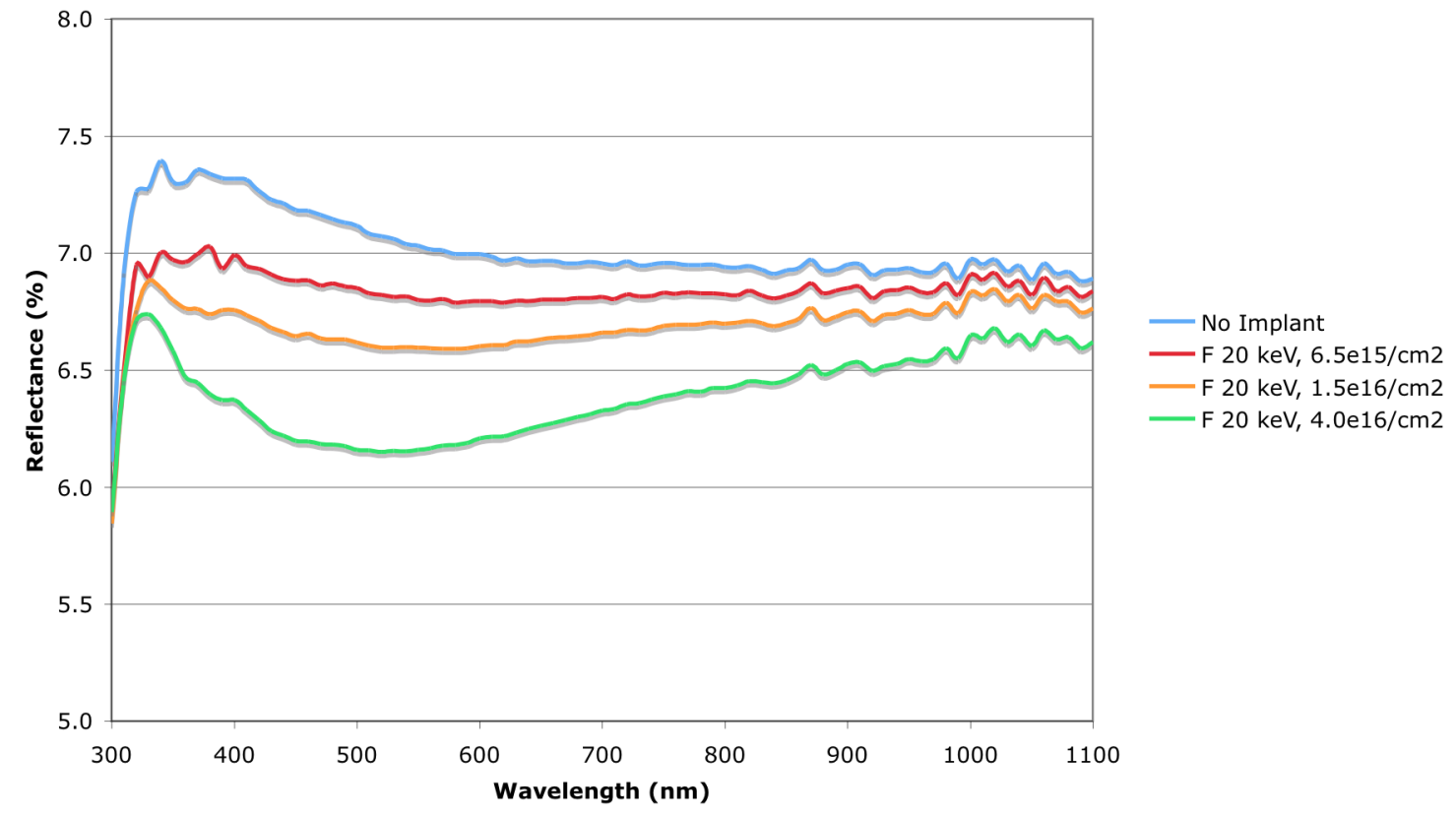

Figure 23. $\mathrm{F}^{+}$implantation into Borofloat glass at $20 \mathrm{keV}$ for three doses.

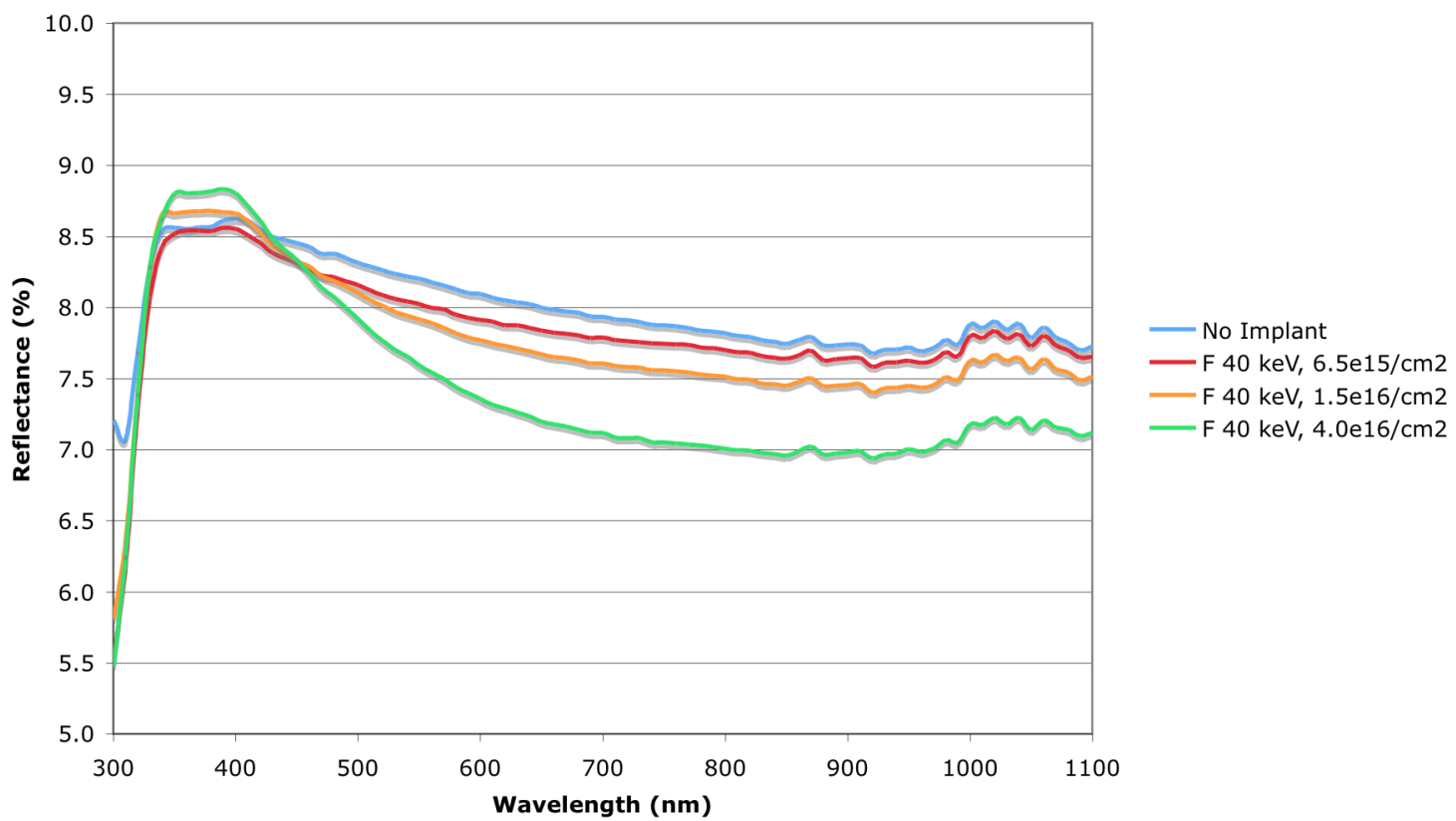

Figure 24. $\mathrm{F}^{+}$implantation into Optiwhite glass at $40 \mathrm{keV}$ for three doses. 


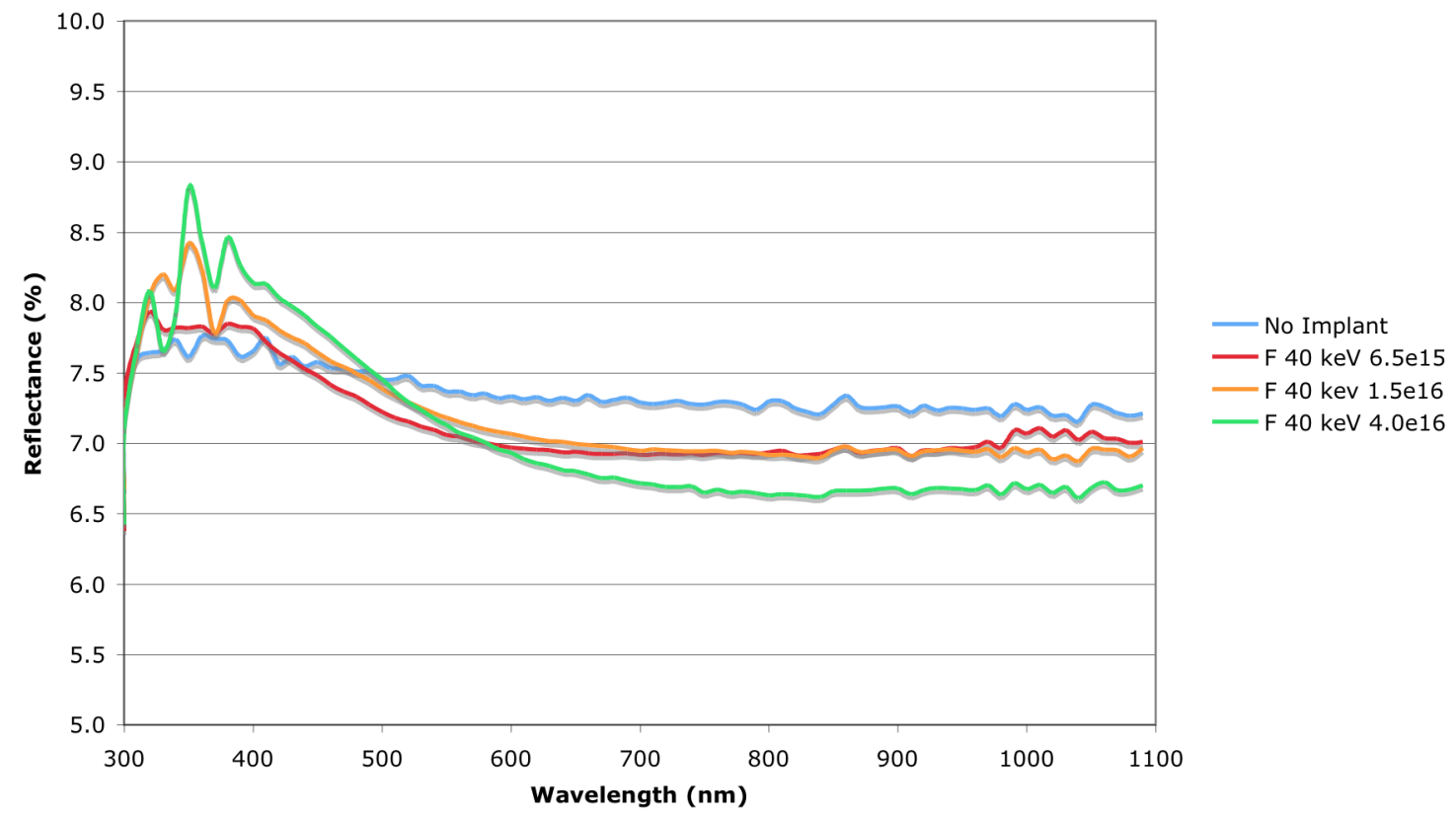

Figure 25. $\mathrm{F}^{+}$implantation into Borofloat glass at $40 \mathrm{keV}$ for three doses.

\subsection{Anneal Testing of Fluorine Implants}

One hypothesis in his work is that the F can form ionic bonds with other elements in the glass matrix and, by changing the polarizability, change the index of refraction. This bonding might be facilitated by a thermal anneal. Therefore, we tested annealing of the F-implanted glass samples described in section 4.1. The annealing was carried out in two steps. The first cycle was $300 \mathrm{C}$ for $30 \mathrm{~min}$. The second cycle was $500 \mathrm{C}$ for 30 $\min$.

Figures 26 and 27 show the results of annealing $\mathrm{F}^{+}$-implanted Optiwhite glass, and Figures 28 and 29 show the result for Borofloat glass. For Optiwhite glass, the F implant is more effective without annealing in every case for both $20 \mathrm{keV}$ and $40 \mathrm{keV}$ implant energy. For Borofloat glass implanted at $20 \mathrm{keV}$ (Fig. 28), the F implant is more effective without the annealing. At $40 \mathrm{keV}$, may provide a small benefit.

Three mechanisms are probably at work within the glass during annealing: ionic bounding of F, diffusion of F, and annealing of the glass itself. Figures 30 and 31 show the data for $40 \mathrm{keV}, 4 \times 10^{16} / \mathrm{cm}^{2}$ implants replotted and compared to glass before and after annealing. Fig. 30 shows that annealing reverses the reduction of reflectance of Optiwhite glass. Probably this is a result of a combination of diffusion of $F$ within the glass, and annealing of the glass itself, which we showed earlier causes an increase in reflectance. For the case of Borofloat, annealing of the glass causes a small decrease in reflectance. During the anneal, diffusion of $\mathrm{F}$ would tend to increase reflectance while annealing would tend to decrease reflectance. Fig. 31 shows that the result of annealing F-implanted Borofloat glass is reflectance that is approximately the same as unimplanted, annealed Borofloat glass. This indicates to us that F diffuses within both glasses, and that annealing is not useful to improve the action of the $\mathrm{F}$. 
FINAL REPORT

CONTRACT DE-EE0000590
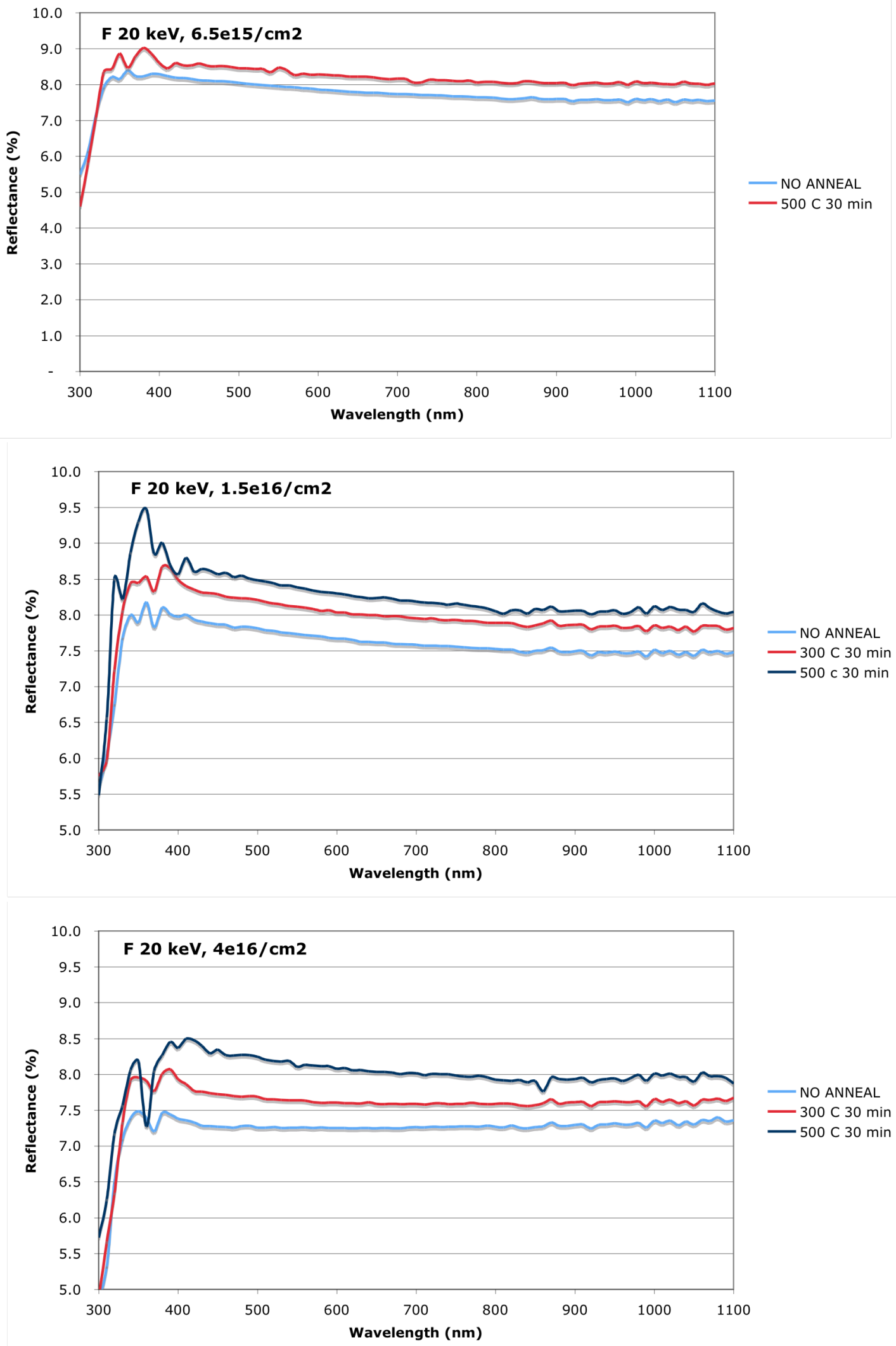

Figure 26. Reflectance of $\mathrm{F}^{+}$implanted at $20 \mathrm{keV}$ in Optiwhite glass. 
FINAL REPORT

CONTRACT DE-EE0000590
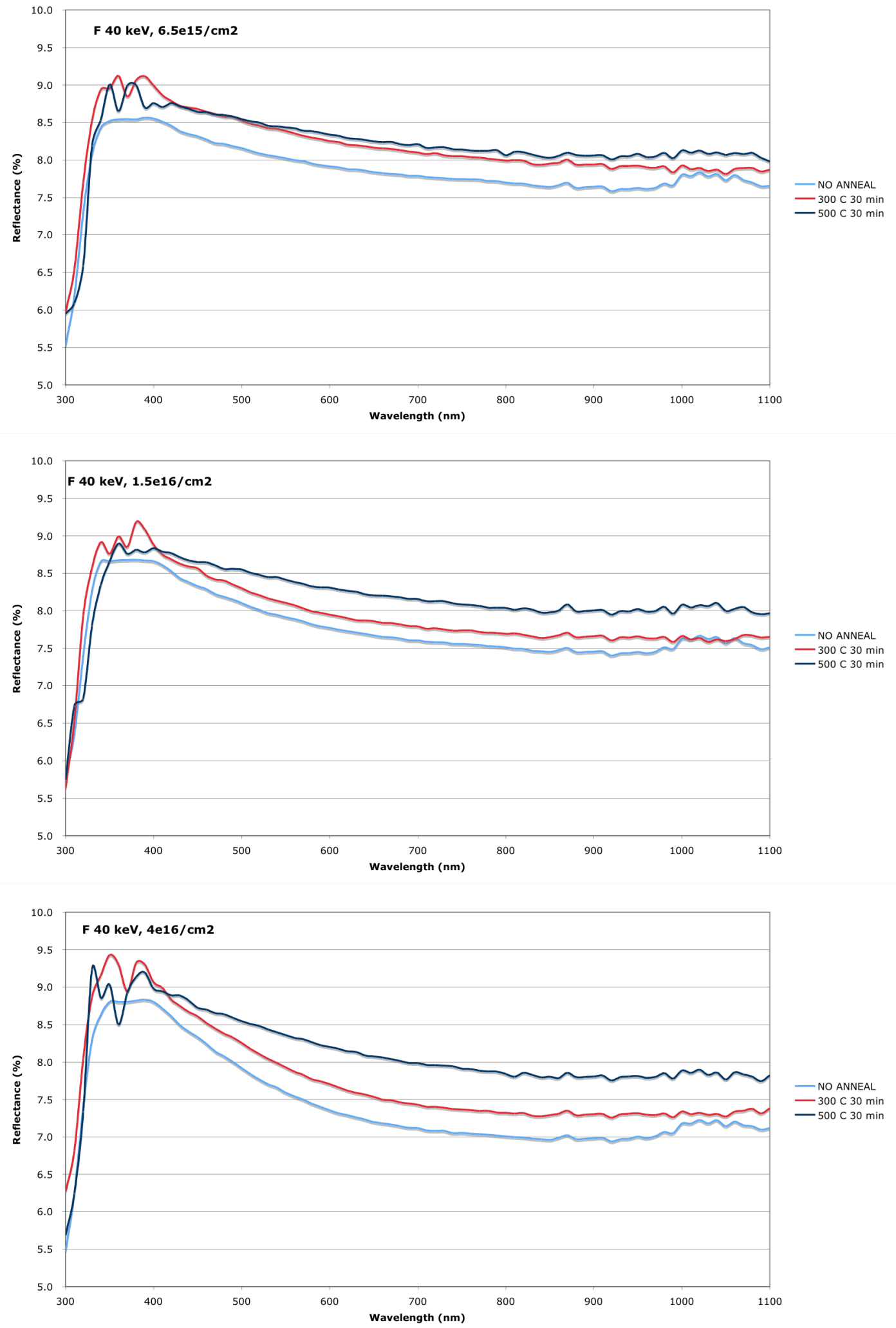

Figure 27. Reflectance of $\mathrm{F}^{+}$implanted at $40 \mathrm{keV}$ in Optiwhite glass before and after annealing. 
FINAL REPORT

CONTRACT DE-EE0000590
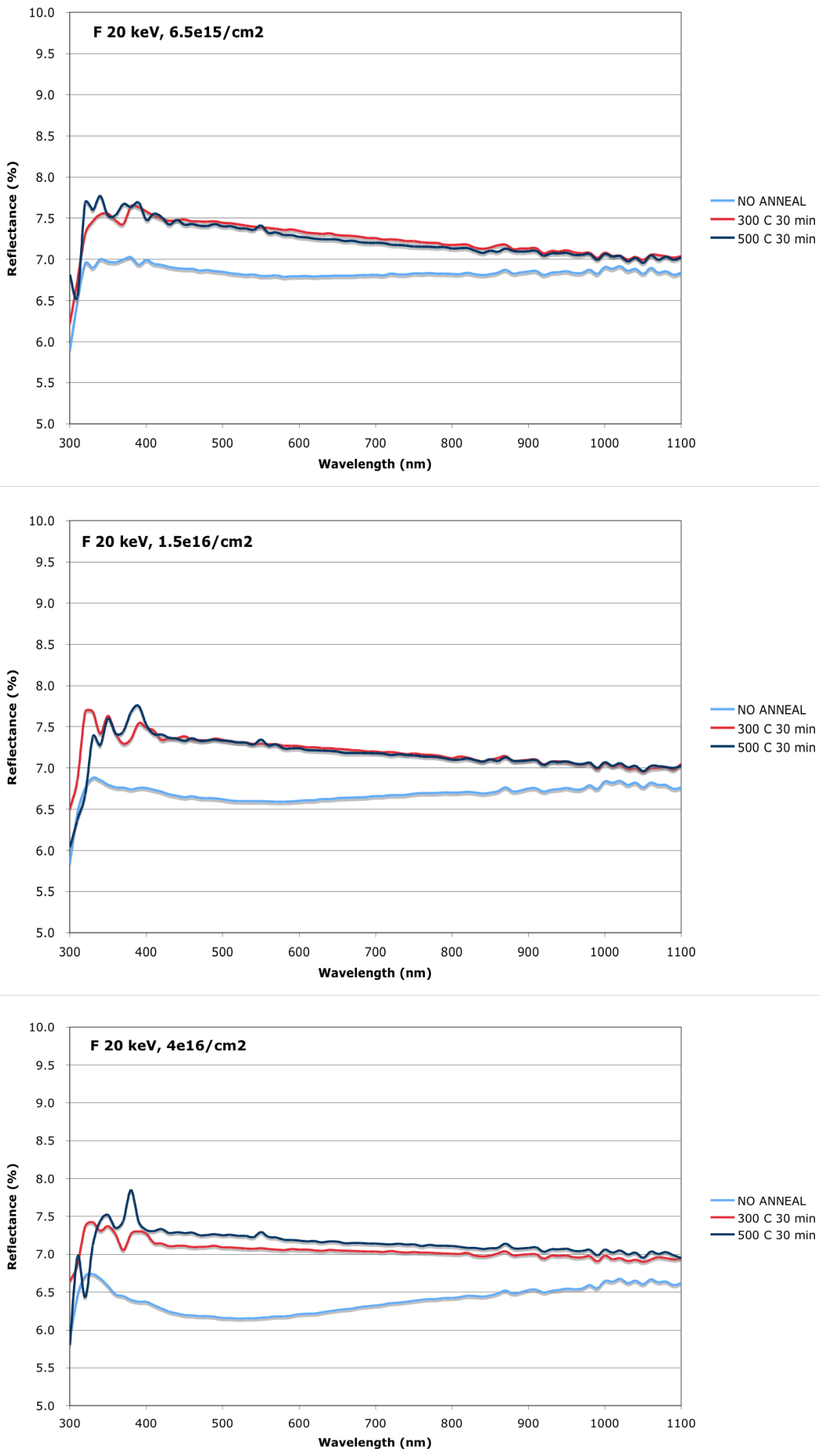

Figure 28. Reflectance of Borofloat glass implanted with $\mathrm{F}$ at $20 \mathrm{keV}$ before and after annealing. 
FIAIA I DEDODT


Figure 29. Reflectance of F-implanted Borofloat glass before and after annealing. 
FINAL REPORT

CONTRACT DE-EE0000590

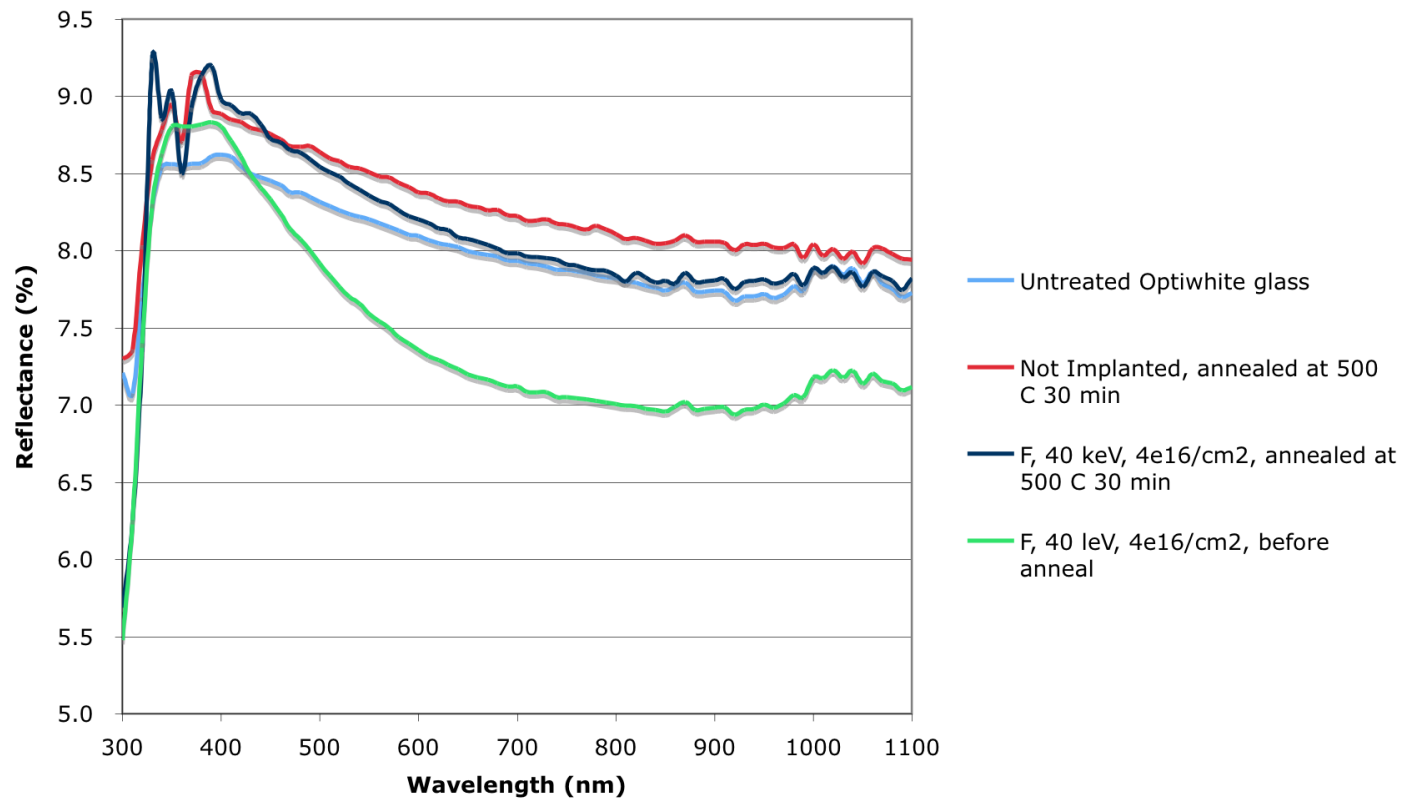

Figure 30. Comparison of annealing F-implanted Optiwhite glass to non-implanted glass.

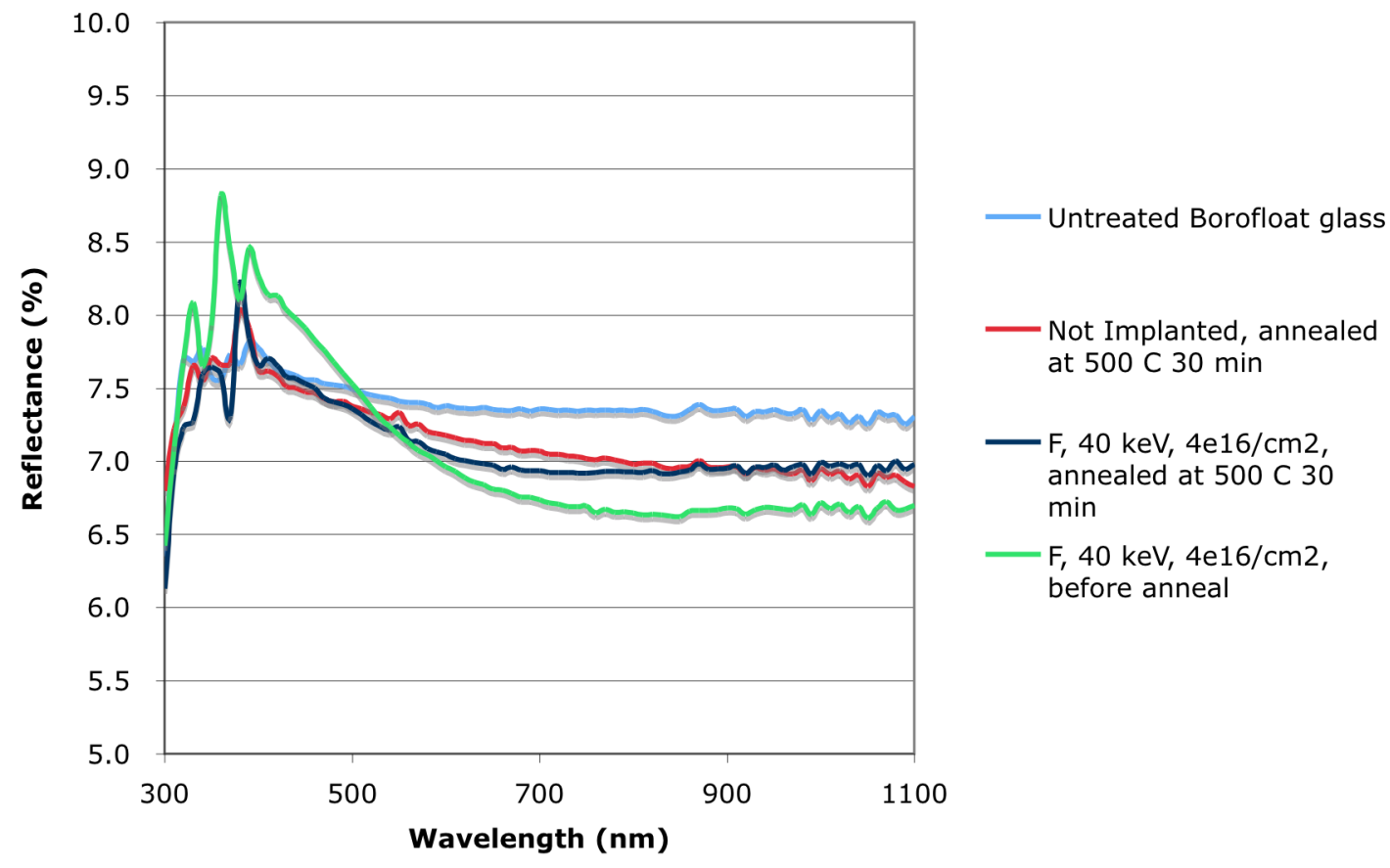

Figure 31. Comparison of annealing F-implanted Borofloat glass to non-implanted glass. 


\subsection{Multiple $\mathrm{F}^{+}$Implantation}

The development of a graded layer has the potential to lower the reflectance and to reduce sensitivity to angle of incidence. In order to created graded layers, we investigated the use of multiple implants of $\mathrm{F}$ and of mixing $\mathrm{F}$ and Ar implantation. Modeling of index of refraction and projected range was carried out to develop a set of implant parameters that would result in a graded layer. Fig. 32 shows the reflectance of Borofloat glass after three such implants. The first experiment comprised formation of a shallow $\mathrm{F}^{+}$implant $\left(10 \mathrm{keV}, 1 \times 10^{16} / \mathrm{cm}^{2}\right.$, followed by $\left.20 \mathrm{keV}, 6.5 \times 10^{15} / \mathrm{cm}^{2}\right)$ to reduce the index of refraction close to the surface. Fig. 32 shows that this implant did reduce the reflectance at short wavelengths, but it had no effect at wavelengths above $650 \mathrm{~nm}$. This corresponds to the formation of a thin quarter-wave layer. A second experiment with a deeper implant $\left(20 \mathrm{keV}, 6.5 \times 10^{16} / \mathrm{cm}^{2}\right.$ followed by $\left.40 \mathrm{keV}, 6.5 \times 10^{16} / \mathrm{cm}^{2}\right)$ produces a wider layer and moves the reflectance minima to about $600 \mathrm{~nm}$.

The final experiment comprised a three-step implant designed to attain a graded layer. The $\mathrm{F}^{+}$implants comprised $10 \mathrm{keV}, 1 \times 10^{16} / \mathrm{cm}^{3}$, followed by $20 \mathrm{keV}, 6.5 \times 10^{16} / \mathrm{cm}^{2}$ followed by $40 \mathrm{keV}, 6.5 \times 10^{16} / \mathrm{cm}^{2}$. This implant schedule resulted in broadening the minima as shown in Fig. 32, however, the reflectance is only reduced by a small amount compared to untreated glass.

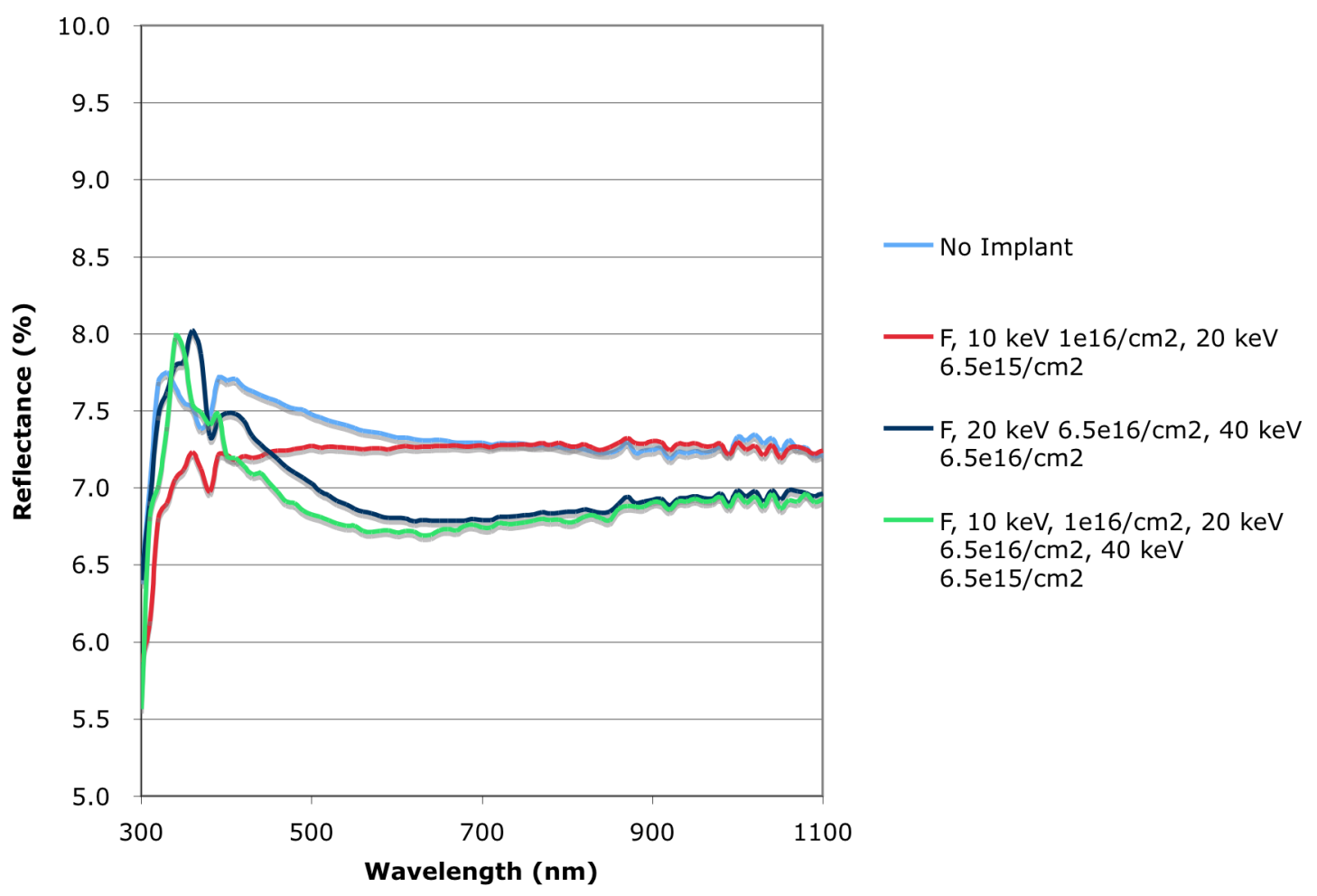

Figure 32. Multiple $\mathbf{F}^{+}$implantation into Borofloat glass.

Multiple F implants into Optiwhite glass were also investigated. Fig. 33 shows a comparison of the three-step implant $\left(10 \mathrm{keV}, 1 \times 10^{16} / \mathrm{cm}^{3}\right.$, followed by $20 \mathrm{keV}$, 
$6.5 \times 10^{16} / \mathrm{cm}^{2}$ followed by $\left.40 \mathrm{keV}, 6.5 \times 10^{16} / \mathrm{cm}^{2}\right)$ to the baseline Ar implant $(50 \mathrm{keV}$, $3 \times 10^{16} / \mathrm{cm}^{2}$ ). Although the $\mathrm{F}$ implant does reduce reflectance, the Ar implant is clearly superior.

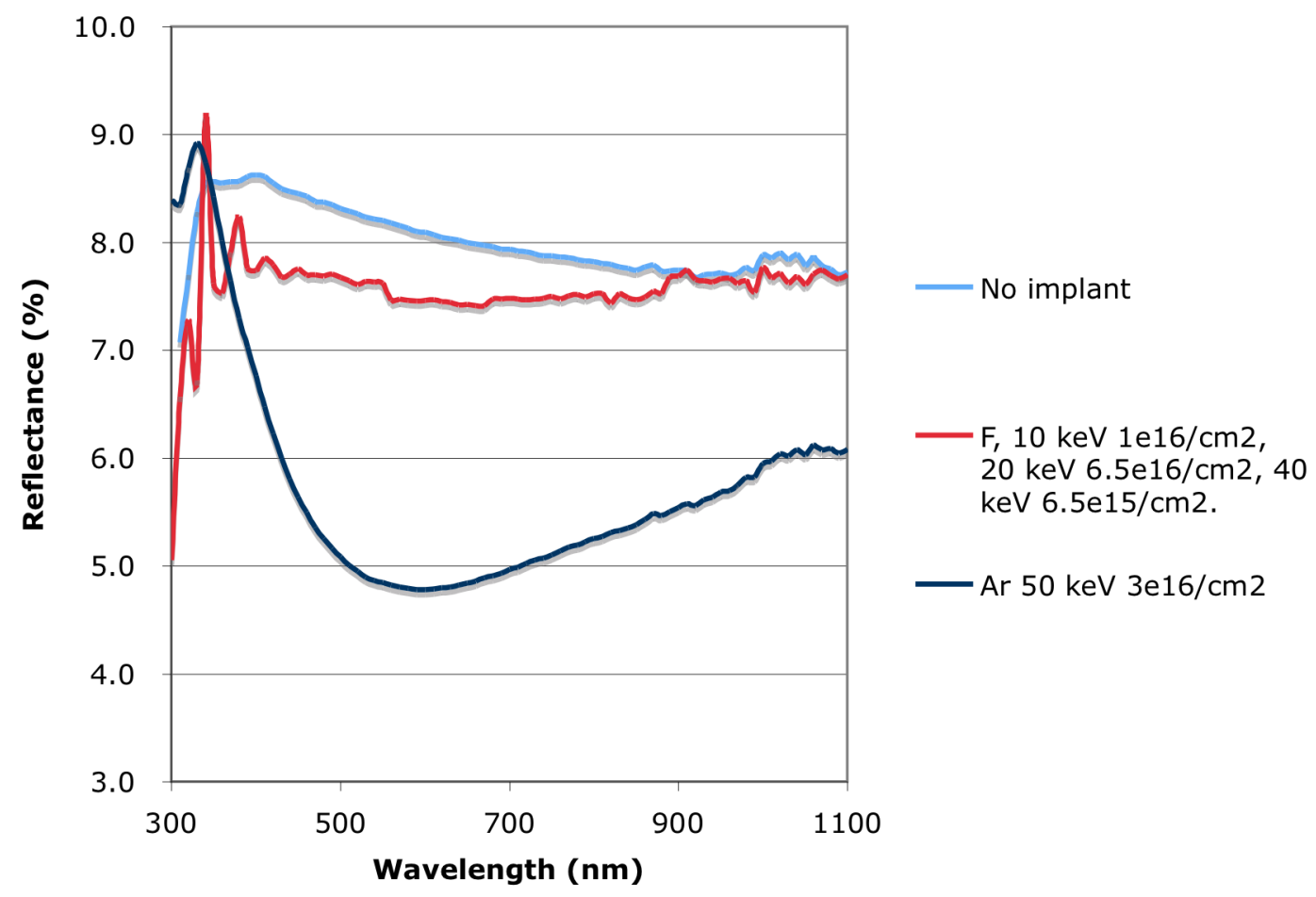

Figure 33. Comparison of reflectance of three-step F+ implant to baseline Ar implant in Optiwhite glass.

\subsection{Mixed $\mathrm{Ar}^{+}$and $\mathrm{F}^{+}$Implants in Borofloat Glass}

The final experiment to reduce the reflectance of Borofloat glass involved mixing Ar and $\mathrm{F}$ implants. Fig. 34 shows the resulting reflectance, in which we have also plotted the reflectance from single $\operatorname{Ar}\left(50 \mathrm{keV}, 1 \times 10^{17} / \mathrm{cm}^{2}\right)$ and $\mathrm{F}$ implants (40 $\mathrm{keV}$, $4 \times 10^{16} / \mathrm{cm}^{2}$ ). The single Ar implant is inferior to any of the implants with $\mathrm{F}$. However, the implant schedule that performs the best comprises $\mathrm{Ar}$ at $50 \mathrm{keV}, 1 \times 10^{17} / \mathrm{cm}^{2}$, followed by $\mathrm{F}$ at $40 \mathrm{keV}, 1.5 \times 10^{16} / \mathrm{cm}^{2}$. It is possible that the Ar damages the atomic bonding in the glass, making it easier for $\mathrm{F}$ to form bonds. If this is the case, it is possible that annealing would improve the $\mathrm{F}$ bonding. We examined this sample after annealing at $300 \mathrm{C}$ and $500 \mathrm{C}$. Fig. 35 shows that the annealing has no meaningful effect on the reflectance. The mechanism at work in the Ar and F implanted samples is not understood. 


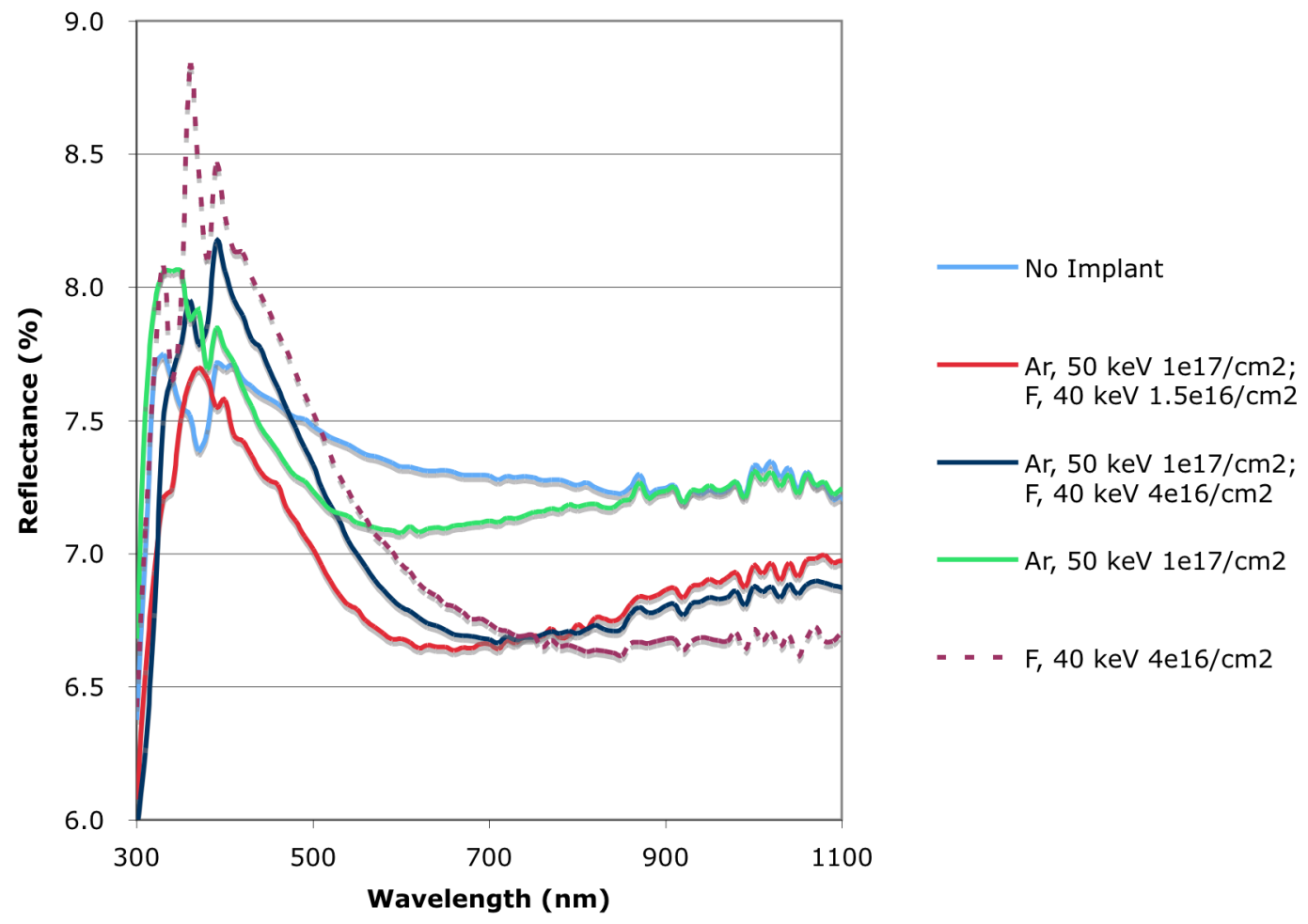

Figure 34. Borofloat glass implanted with $\mathrm{F}^{+}$and $\mathrm{Ar}^{+}$.

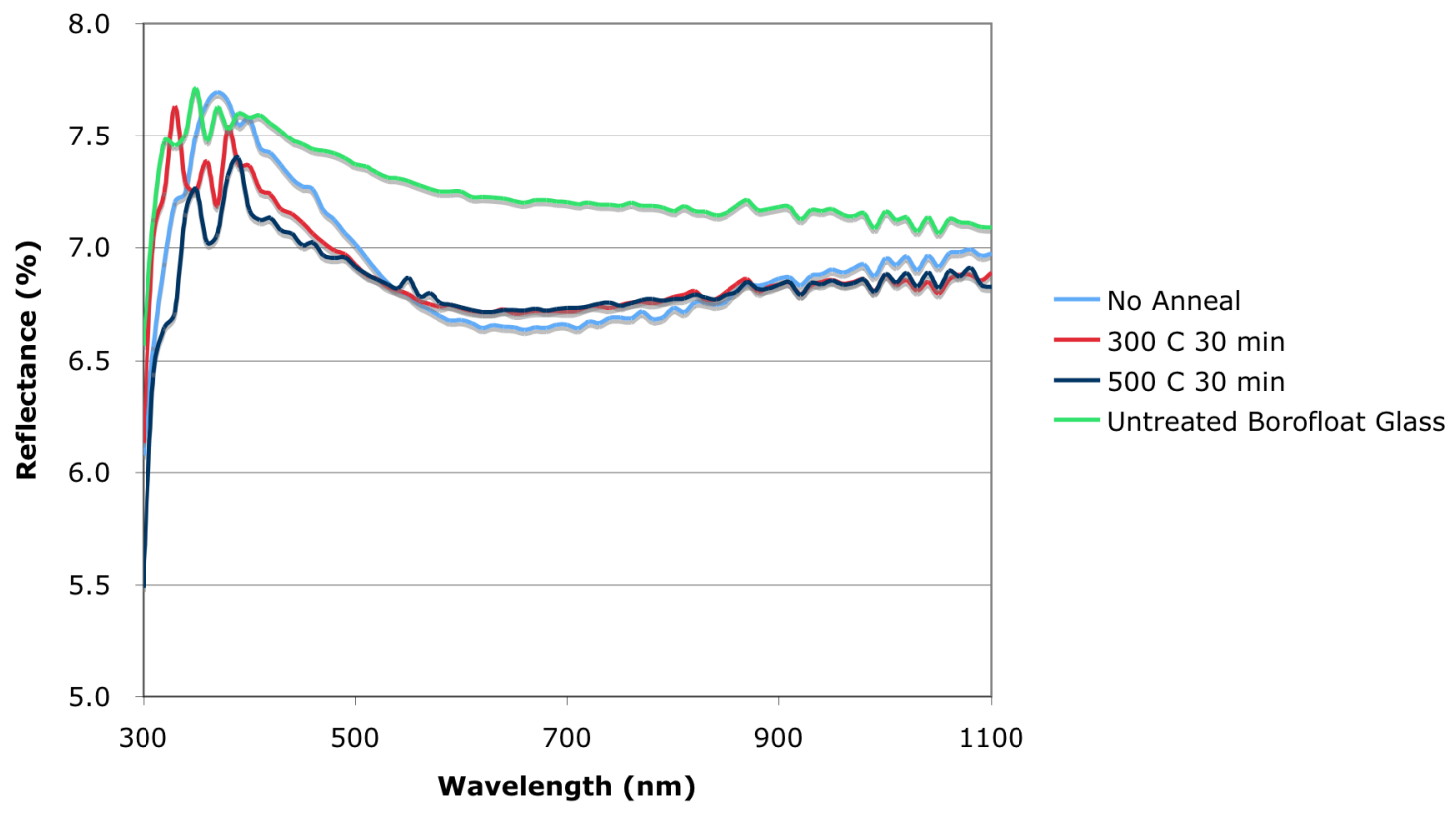

Figure 35. Annealing of Borofloat glass implanted with $\operatorname{Ar}\left(50 \mathrm{keV}, 1 \times 10^{17} / \mathrm{cm}^{2}\right)$ and $F\left(40 \mathrm{keV}, 1.5 \times 10^{16} / \mathrm{cm}^{2}\right)$. 


\subsection{Architectural Glass}

Applicability of ion implantation for control of transmission and reflectance of architectural glass was also studied. Fig. 36 shows the reflectance of Optiwhite compared to generic soda-lime architectural (window) glass. The two glass types have similar reflectance before implant, and the Ar implant is effective in both materials.

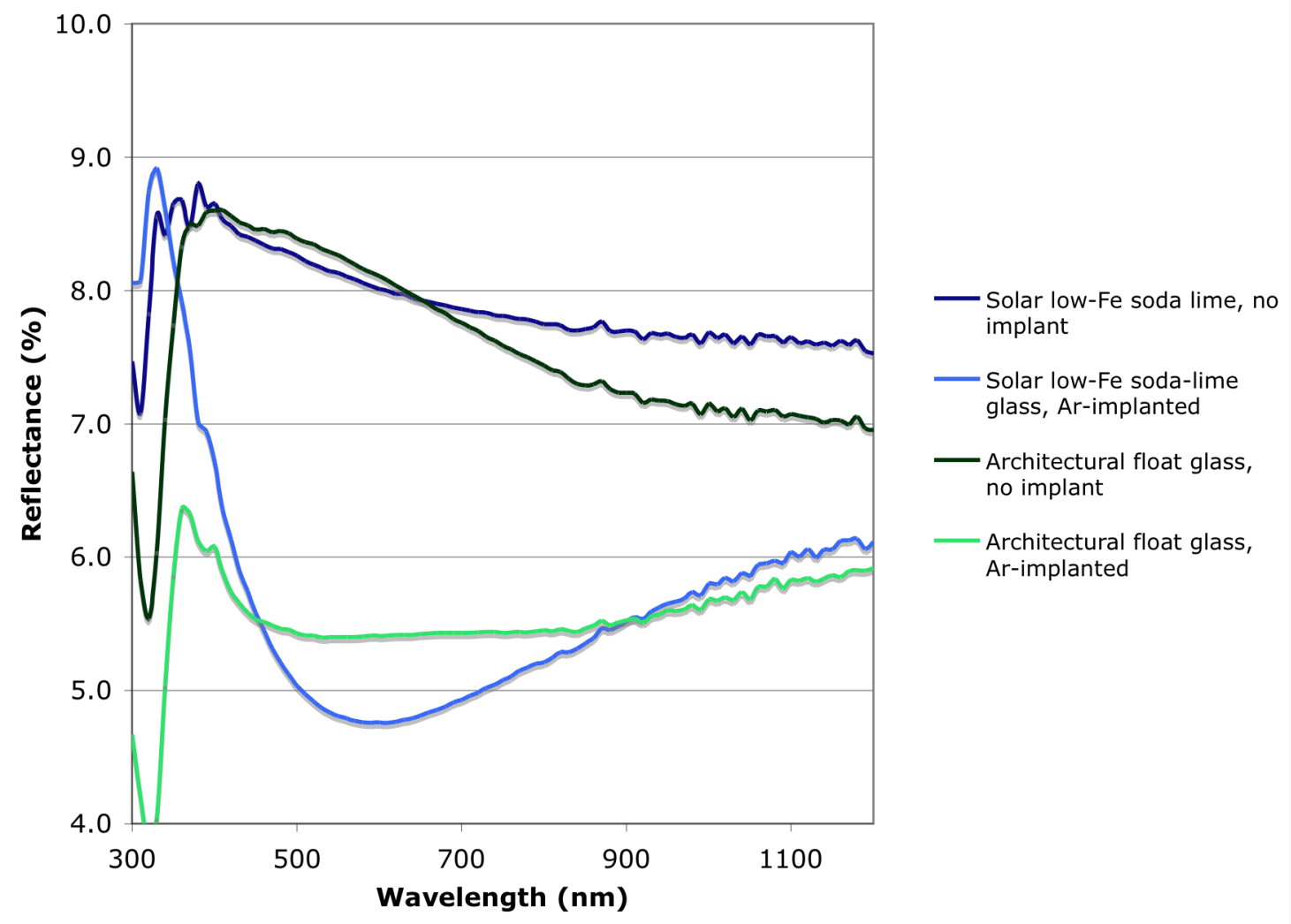

Figure 36. Comparison of Ar implantation of Optiwhite glass and generic architectural window glass. The implant was at $50 \mathrm{keV}, 3 \times 10^{16} / \mathrm{cm}^{2}$.

We also examined the transmission of soda lime float glass before and after $\mathrm{N}^{+}$ implantation into generic architectural glass. Fig. 37 shows that the transmission is not improved by $\mathrm{N}^{+}$implantation. However, Fig. 38 shows that Xe does improve the transmission, presumably in a manner comparable to Ar and $\mathrm{Kr}$. 


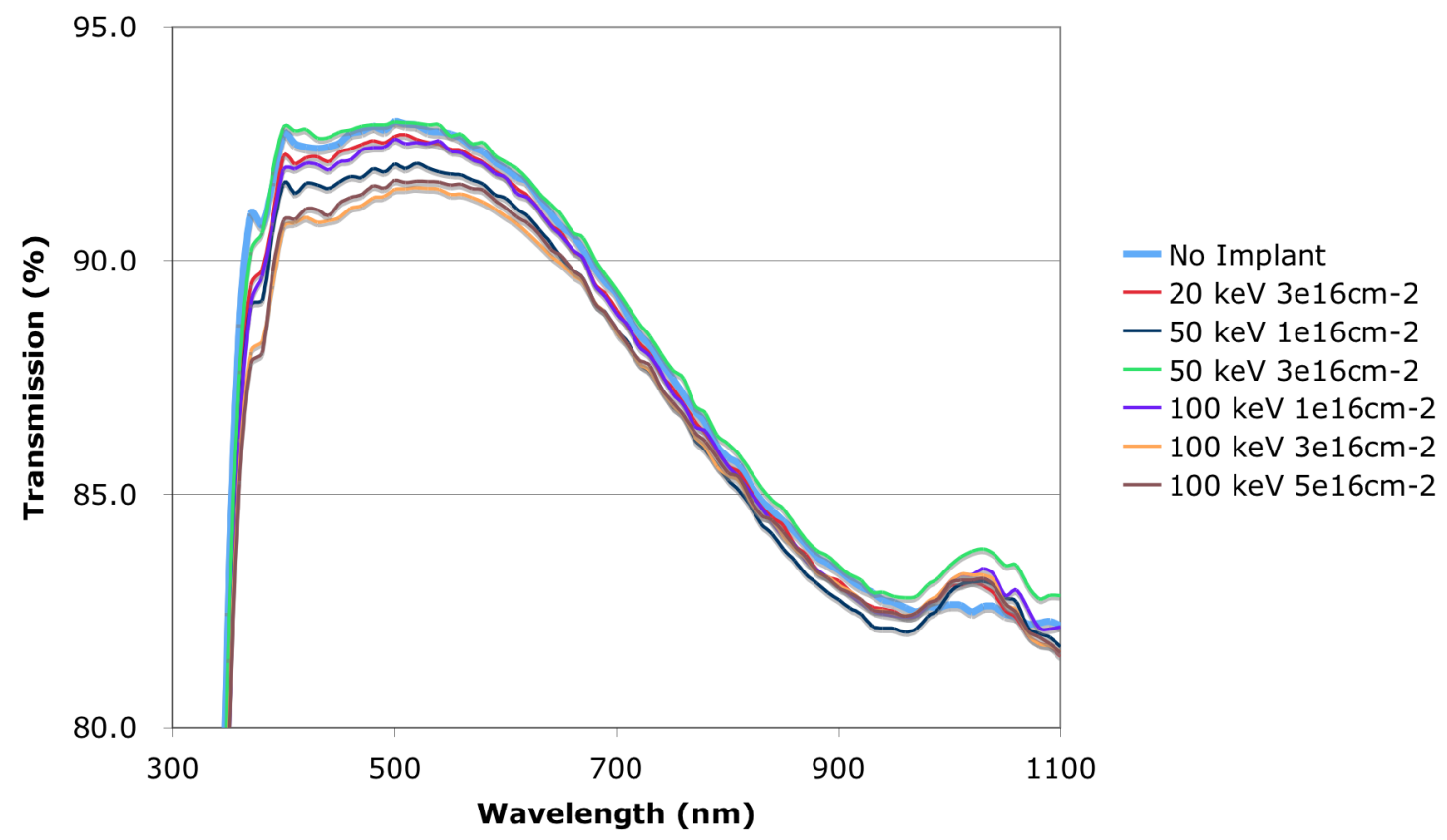

Figure 37. Transmission of soda lime float glass after $\mathbf{N}^{+}$implantation.



Figure 38. Transmission of soda lime float glass after $\mathrm{Xe}^{+}$implantation. 
Table 1 provides a summary of the applicability of ion implantation in three solar markets. In passive solar and architectural applications, the change in reflectance is high in both types of soda lime glass. Although we have focused on obtaining low reflectance, implantation can also be used to increase or decrease reflectance in architectural glass. Applicability of implantation of borosilicate glass is these markets is low because borosilicate glass is expensive, and the reduction in reflectance is small.

In flat plate markets, the applicability of implantation to low-Fe soda lime glass is high because the reduction in reflectance is large. The process is not particularly applicable to borosilicate glass because the gains are low, and borosilicate glass is not used extensively for flat plate.

Concentrators may use either low-Fe soda lime glass or borosilicate glass. If the front surface of point focus concentrator lenses is formed from low-Fe soda lime, the process is certainly applicable. For interior parts such as secondary optical elements or internal cell covers made from borosilicate glass, the applicability is rated as medium-tolow, because there is an effect from ion implantation, but it is not large. It is likely that a better result can be attained from $\mathrm{MgF}_{2}$ at a lower cost.

Table 1. Applicability of ion implantation to solar markets.

\begin{tabular}{|l|c|c|c|}
\hline Solar Application & $\begin{array}{c}\text { Standard } \\
\text { Soda-lime }\end{array}$ & $\begin{array}{c}\text { Low-Fe } \\
\text { Soda-lime }\end{array}$ & Borosilicate \\
\hline Passive solar & high & high & low \\
\hline Flat Plate & N/A & high & low \\
\hline Concentrator & N/A & high & medium \\
\hline
\end{tabular}




\subsection{COST JUSTIFICATION}

We have made an analysis of the allowable cost of the Ar implant process for both flat plate and concentrator modules, based on reduction of reflectance from $4 \%$ to $1 \%$. Table 3 shows the results of the analysis. We assume a baseline cell efficiency of $18 \%$ the baseline case includes a total weighted reflectance loss of $4 \%$, electrical losses of $1 \%$ and packing efficiency of $95 \%$. The resultant total baseline module efficiency is $16.3 \%$. For the Ar-implanted module, we assume a reduction in total weighted reflectance to $1 \%$, with other factors unchanged. The Ar-implanted module has an efficiency of $16.8 \%$. The power per $\mathrm{m}^{2}$ is $163 \mathrm{~W}_{\mathrm{p}}$ for the baseline and $168 \mathrm{~W}_{\mathrm{p}}$ for the Arimplanted module.

The current cost per watt of flat plate modules is about $2.65 \$ / \mathrm{Wp}$ (www.solarbuxzz.com). Therefore, the price of the baseline module is $\$ 431 / \mathrm{m}^{2}$, as shown in Table 3. This is also the price of the Ar-implanted module, excluding implant costs. As the table shows, if we allow a cost of $13 / \mathrm{m}^{2}$ for the Ar implant, we attain the same cost per watt as the baseline module. Therefore, this is the upper limit to the allowable cost for the implant.

Table 3. Cost Calculation for Ar-implanted Flat Plate Module.

\begin{tabular}{|c|c|c|}
\hline & $\begin{array}{l}\text { BASELINE } \\
\text { MODULE }\end{array}$ & $\begin{array}{l}\text { IMPLANTED } \\
\text { MODULE }\end{array}$ \\
\hline CELL EFFICIENCY & $18 \%$ & $18 \%$ \\
\hline REFLECTANCE & $4 \%$ & $1 \%$ \\
\hline ELECTRICAL LOSSES & $1 \%$ & $1 \%$ \\
\hline PACKING FACTOR & $95 \%$ & $95 \%$ \\
\hline PANEL EFFICIENCY & $16.3 \%$ & $16.8 \%$ \\
\hline POWER OUTPUT $\left(\mathrm{W} / \mathrm{m}^{2}\right)$ & 163 & 168 \\
\hline $\begin{array}{l}\text { PANEL COST EXCLUDING } \\
\text { IMPLANT }\left(\$ / W_{p}\right)\end{array}$ & 2.65 & 2.65 \\
\hline $\begin{array}{l}\text { AREA COST BEFORE Ar } \\
\text { IMPLANT }\left(\$ / \mathrm{m}^{2}\right)\end{array}$ & 431 & 431 \\
\hline IMPLANT COST $\left(\$ / \mathrm{m}^{2}\right)$ & & 13 \\
\hline TOTAL PANEL COST & 431 & 444 \\
\hline COST WITH IMPLANT (\$/W) & & 2.65 \\
\hline
\end{tabular}


The second question we addressed is whether an ion implanted can be built that offers the required Ar dose for $\$ 13 / \mathrm{m}^{2}$. This would require a low cost high current machine. Our work shows that that the glass is not very sensitive to dose, and is most likely insensitive to small amounts of impurities. Therefore, a glass implanter does not need mass analysis, and dose uniformity requirements need not be better than $50 \%$. The low energy $(50 \mathrm{keV})$ means that a second stage of acceleration is not required. Gas handling equipment for Ar is minimal. Therefore, the ion implanted needed for glass implantation would comprise mainly a glass transport system and a high current ion engine. We speculate that such an implanter could be built and sold profitably for less than \$1M. Maintenance on an implanter running only $\mathrm{Ar}^{+}$could be expected to be minimal, meaning that annual operating costs should be less than $200 \mathrm{~K} / \mathrm{yr}$.

If a current of $200 \mathrm{~mA}$ can be attained, such an implanter would be capable of $1.25 \times 10^{18}$ ions/s. The dose required is $3 \times 10^{16} / \mathrm{cm}^{2}$. One square meter would require 4 min. If the implanter runs three shifts with the fourth shift for maintenance $(6,000$ hours per year), the throughput of the implanter is $90,000 \mathrm{~m}^{2}$ of glass per year.

Assuming the implanter price of $\$ 1 \mathrm{M}$ is amortized at $200 \mathrm{~K} / \mathrm{yr}$ with an operating cost of $200 \mathrm{k} / \mathrm{yr}$, then the annual cost is $\$ 400 \mathrm{~K}$ to process $90,000 \mathrm{~m}^{2}$. The cost is then roughly $\$ 4.4 / \mathrm{m}^{2}$. Well within the requirement shown in Table 3. Thus, if high current is attained, the process is feasible. 
FINAL REPORT

CONTRACT DE-EE0000590

\subsection{CONCLUSIONS}

We have shown that Ar implantation can reduce reflectance of soda lime and borosilicate glass. The effect is much stronger in soda lime glass. The reduction in reflectance is superior to conventional single layer coatings of $\mathrm{MgF}_{2}$. We find the optimal Ar ion implantation parameters to be:

$\begin{array}{ll}\text { Species: } & \mathrm{Ar} \\ \text { Energy: } & 50 \mathrm{keV} \\ \text { Dose: } & 3 \times 10^{16} \text { ions } / \mathrm{cm}^{2} .\end{array}$

The process is highly applicable to flat plate modules. It may also be useful in point focus concentrator modules that use soda lime glass as the exterior surface of the Fresnel lens. At its present stage of development, it does not appear to have sufficient advantages over thin film coatings to be applicable to borosilicate glass optics internal to the concentrator system.

We were not able to develop a graded index layer in this work. We speculate that this is a result of the change in projected range that results from the formation of microvoids. Nevertheless, a graded index layer is possible, but it will require a careful use of cross sectional TEM to correlate energy, does and micro-void formation. More work is required in this area. Such work might also be used to develop a process for application to borosilicate glass.

The Ar implant process has commercial promise. The cost can be sufficiently low if very high current ion sources are used. The process is insensitive to non-uniformity and impurities, and does not require especially high energy. The use of Ar is safe and effluent free, and is likely to require little ion source maintenance.

\subsection{ACKNOWLEDGEMENTS}

We are grateful to Varian Semiconductor Equipment Associates, and in particular J. England and M. Evans, for performing the ion implantation in this work, and for helpful discussions and analysis. 


\section{REFERENCES}

1. M. Neander, F. Gromball, D. Neumann, N.-P. Harder, W. Nositschka, "Antireflection Coating Tuned for Higher Solar Module Voltage," Record of the IEEE $4^{\text {th }}$ World Conf. on Photovoltaic Energy Conversion, p. 2070 (2006).

2. J. Zhao, A. Wang, P. Campbell, and M. Green, " $22.7 \%$ Efficient Photovoltaic Modules with Textured Front Surface," IEEE Trans. Electron Devices 46, p. 1495 (1995).

3. P. Sánchez-Friera, D. Montiel, J. Gil, J. Montañez, and J. Alonso, "Daily Power Output Increase of Over 3\% With the Use of Structured Glass in Monocrystalline Silicon PV Modules," Record of the IEEE $4^{\text {th }}$ World Conference on Photovoltaic Energy Conversion, p. 2156 (2006).

4. See for example the recent " $1{ }^{\text {st }}$ PV Glass Conference," Shenzhen, China, January $18,2008$.

5. J. Meyer-Arendt, "Introduction to Classical and Modern Optics," Prentice-Hall, (1995), see p. 217 for magnesium fluoride reference, and p. 122-126 for graded index lens and fiber references.

6. V. Chinellatov, V. Gottardi, S. Lo Russo, P. Mazzoldi, F. Nicoleti, and P. Polato, "Optical, Chemical and Mechanical Modifications Induced by Ion Implantation on Glass Surfaces," Radiation Effects, 65 p. 31 (Gordon and Breach Science Publishers, Inc., 1982), Presented at the First International Conference on Radiation Effects In Insulators," Arco, Lago di Garda, 1981.

7. A. A. Deshkovskaya, "Ion Implantation in Glasses and Concomitant Effects," Radiation Effects, 103, p. 149 (1987).

8. P. Polato, P. Mazzoldi, and A. B. Boscoletto, "Characterization by Nuclear and Spectrophotometric Analysis of Near-surface Modifications of Glass Implanted with Heavy Ions," J. Am. Ceram. Soc., 70, p. 775 (1987).

9. S. Fantone, "Refractive index and spectral models for gradient-index materials," Applied Optics Vol. 22, p. 432 (1983). 


\section{APPENDIX}

Publications resulting from this work.

ION BEAM SURFACE MODIFICATION OF SOLAR MODULE GLASS FOR REDUCED REFLECTANCE, by Mark B. Spitzer (Photonic Glass Corporation) and Jonathan England, (Varian Semiconductor Equipment Associates), presented at the $35^{\text {th }}$ IEEE Photovoltaic Specialists Conference, Honolulu (2010). 


\title{
ION BEAM SURFACE MODIFICATION OF SOLAR MODULE GLASS FOR REDUCED REFLECTANCE
}

\author{
Mark B. Spitzer ${ }^{1}$ and Jonathan England ${ }^{2}$ \\ ${ }^{1}$ Photonic Glass Corporation, Norwood, MA, USA \\ ${ }^{2}$ Varian Semiconductor Equipment Associates, Gloucester, MA, USA
}

\begin{abstract}
The surface reflectance of low-iron soda-lime glass imposes a $4 \%$ power loss in most flat plate modules. Optical coatings and surface textures are two approaches to decreasing this loss. In this paper we report on a third method comprising ion implantation of argon to adjust the index of refraction of the near surface region. We show that ion implantation provides a $50 \%$ reduction in the reflectance. This method appears to have general applicability owing to the wide use of soda-lime glass in module manufacturing.
\end{abstract}

\section{INTRODUCTION}

Implantation studies performed in the 1980s [1-5] showed that reflectance of soda-lime glass could be changed by implantation of Ar ions. The change in index of refraction was attributed to $\mathrm{Na}$ depletion near the surface of the glass. Our objective is to gain a better understanding of the physical changes in the glass matrix introduced by the ion beam so that we can tailor the index of refraction to very low surface values without introducing a thin film coating. When applied to photovoltaic module glass, this modification can improve short circuit current and may have better durability than conventional coatings.

As a benchmark for our work, we calculated the performance of an ideal $\mathrm{MgF}_{2} \mathrm{AR}$ coating. Such a coating, optimized for a Si photovoltaic module, has a thickness of $115 \mathrm{~nm}$. The solar-weighted average reflectance (defined later) is $1.9 \%$. In comparison, the solar-weighted average reflectance of uncoated low-Fe soda lime glass is $4 \%$, meaning that $\mathrm{MgF}_{2}$ could provide a substantial reduction in reflectance. We will show that even better results can be attained by ion implantation of Ar.

In the work to be reported here, two glass materials were evaluated: Optiwhite ${ }^{\mathrm{TM}}$ low-Fe soda-lime glass (Pilkington), and Borofloat ${ }^{\mathrm{TM}}$ borosilicate glass (Schott). All samples were $50 \mathrm{~mm} \times 50 \mathrm{~mm} \times 3 \mathrm{~mm}$. The Optiwhite samples are representative of glass used in conventional solar modules, and since previous work [3] identified $\mathrm{Na}$ depletion as the mechanism affecting index of refraction, the Borofloat samples served as low-Na controls.

\section{SAMPLE PREPARATION AND MEASUREMENTS}

All materials were ion-implanted with Ar using a Varian medium-current $(\sim 2 \mathrm{~mA})$ ion implanter. The sodalime and borosilicate glass samples were loaded on a carrier that held both samples side by side, guaranteeing that each sample received the same implant. An electron flood gun was used to minimize sample charging. Maximum sample temperature measured during the highest energy and longest duration implant was found to be less than $200^{\circ} \mathrm{C}$, providing confidence that none of the samples reached elevated temperatures that would interfere with our experiment.

An examination of projected range of $\mathrm{Ar}$ in soda lime glass indicated that energy range of interest was between 25 and $75 \mathrm{keV}$. Previous work [1-5] indicated that an implant dose in the range of $10^{16} \mathrm{~cm}^{-2}$ would produce layers of reduced index of refraction. Accordingly, the doses studied in this work ranged from $5 \times 10^{15} \mathrm{~cm}^{-2}$ to $5 \times 10^{16} \mathrm{~cm}^{-2}$. For both borosilicate and soda-lime glass, control samples were measured that had no ion implantation.

After ion implantation, the total reflectance of all samples was measured at $10 \mathrm{~nm}$ intervals in the range $300 \mathrm{~nm}$ to $1100 \mathrm{~nm}$, using a PV Measurements reflectance spectrometer and integrating sphere with a wavelength resolution of about $1 \mathrm{~nm}$. The design of the integrating sphere utilizes a diverging beam entering through a small aperture so that the measurement includes both the specular and diffuse component. The spectrometer was calibrated with a $10 \%$ reflectance standard that was recertified in December 2009 by Avian Technologies. Measurements of specular transmission of the samples indicate that our measurement of total reflectance provides a value that is slightly higher than the true total reflectance. This is most likely a result of the use of a diffuse calibration standard whereas the sample under test is largely specular.

Our measurement of total reflection included the reflection from both surfaces of the glass. For the case of the ion implanted samples, the total reflectance is the sum of the reflectance from the front implanted surface, and the back non-implanted surface. The reflectance of the implanted side can be determined once the reflectance of the back (non-implanted) side is known.

Since absorption in the glass is negligible, we get a very good approximation of the single-side reflectance of the non-implanted controls by assuming that the reflectance from each surface is equal. Thus the singleside reflectance is one half the measured reflectance. This single-side reflectance, obtained from the non-implanted controls, is the same as the single-side reflectance from the back surface of the ion-implanted samples. We determined the single-side front surface reflectance of the ion-implanted samples by subtracting the back reflectance from the total measured reflectance. Measurements of specular transmission confirmed that the absorption is 
minimal in these glasses. Since we are interested comparing the implanted surface to the non-implanted surface, we were not concerned with determining the exact absolute reflectance. Nevertheless, we obtain good correspondence between the measurements and models.

\section{OPTIWHITE REFLECTANCE DATA}

Argon implantation at $50 \mathrm{keV}$ was studied as a function of dose. Measurements of reflectance of Optiwhite samples is shown in Fig. 1, as a function of $\mathrm{Ar}$ dose. Note that in all cases the reflectance was reduced to values less than the control. The reflectance decreases with increased dose to a minimum value, followed by an increase in reflectance as the dose is increased, as has been observed by others [1-5]. The lowest reflectance (Fig. 1f) was obtained with a dose of $3 \times 10^{16} \mathrm{~cm}^{-2}$.

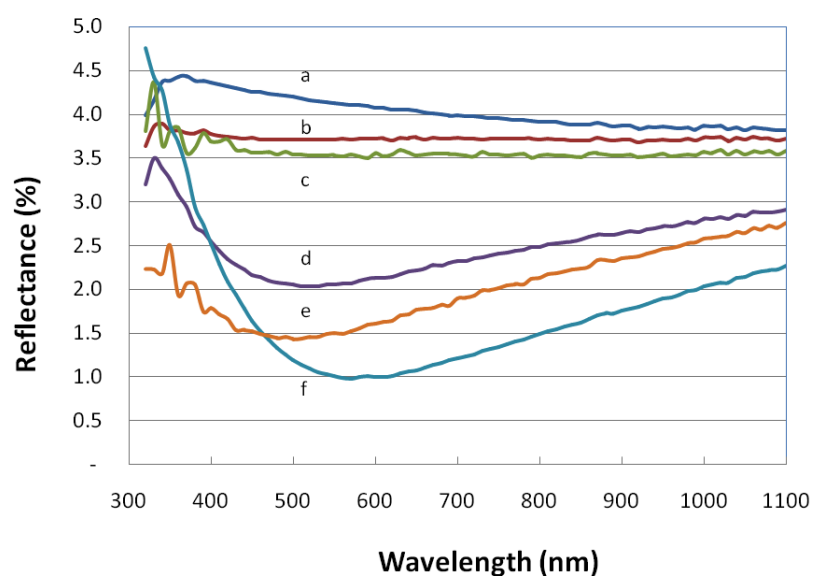

Figure 1 Reflectance of low-Fe soda-lime glass implanted with $\mathrm{Ar}$ at $\mathbf{5 0} \mathrm{keV}$. Implant dose: (a) no implant; (b) $5 \times 10^{15} \mathrm{~cm}^{-2}$; (c) $1 \times 10^{16} \mathrm{~cm}^{-2}$; (d) $2 \times 10^{16} \mathrm{~cm}^{-2}$; (e) $5 \times 10^{16} \mathrm{~cm}^{-2}$; (f) $3 \times 10^{16} \mathrm{~cm}^{-2}$.

We have also investigated the effect of implantation energy on the reflectance of Optiwhite glass, and the result is shown in Fig. 2. It can be seen that as the energy of the implant is increased, the minimum reflectance moves to longer wavelengths. This is consistent with a model in which the higher energy $\mathrm{Ar}$ implant creates a region of reduced index of refraction that is deeper and wider than the region produced by lower energy Ar.

We define the solar-weighted average reflectance as the integration of the product of the reflectance and the AM1.5 photon density, divided by the total number of photons between $300 \mathrm{~nm}$ and $1100 \mathrm{~nm}$. Non-implanted Optiwhite glass has a solar-weighted reflectance of $4.0 \%$. The Ar-implanted sample (50 keV, $3 \times 10^{16} \mathrm{~cm}^{-2}$ ) has a solar-weighted reflectance of $1.5 \%$. This means that the short circuit current of a module can be improved by $2.5 \%$ if the front surface of the glass is implanted with $\mathrm{Ar}$. This is a better reduction than the $1.9 \%$ that can be attained by $\mathrm{MgF}_{2}$.

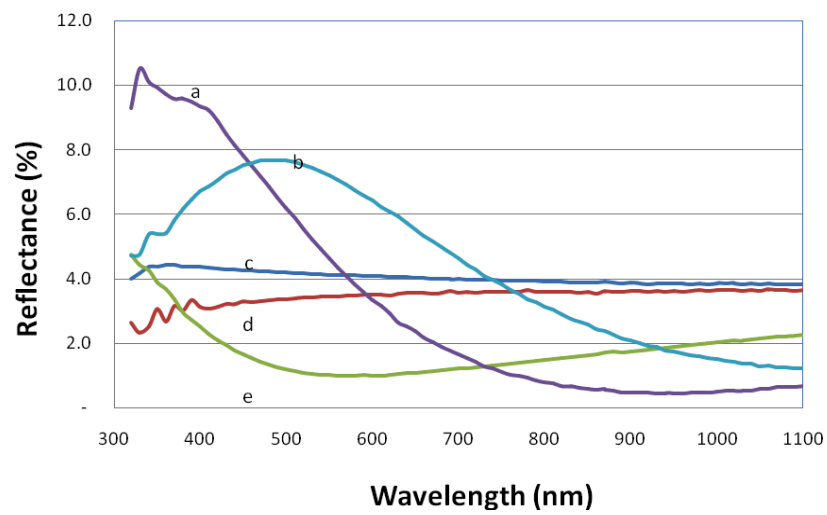

Figure 2 Reflectance of low-Fe soda-lime glass implanted with Ar to a dose of $3 \times 10^{16} \mathrm{~cm}^{-2}$. Energy: (a) $75 \mathrm{keV}$; (b) $105 \mathrm{keV}$; (c) no implant; (d) $22 \mathrm{keV}$, and (e) $50 \mathrm{keV}$.

\section{BOROFLOAT REFLECTANCE DATA}

Fig. 3(a) shows the reflectance of the nonimplanted Borofloat glass implanted with $\mathrm{Ar}$ at $50 \mathrm{keV}$. The unimplanted Borofloat reflectance is slightly lower than the Optiwhite owing to a lower index of refraction. Turning to the implanted samples (b-f), a similar result is observed in the Borofloat in which a dose of $3 \times 10^{16} \mathrm{~cm}^{-2}$ produces the lowest reflectance, yet the magnitude of the change is not as high. The dependence of reflectance on Ar implant energy is shown in Fig. 4. An energy of $50 \mathrm{keV}$ appears to be best, but the effect is small. The solar weighted reflectance of the borosilicate glass is $3.6 \%$. In the best case $\left(50 \mathrm{keV}, 3 \times 10^{16} \mathrm{~cm}^{-2}\right)$, we have reduced the solar weighted reflectance to $3.4 \%$ by Ar implantation.

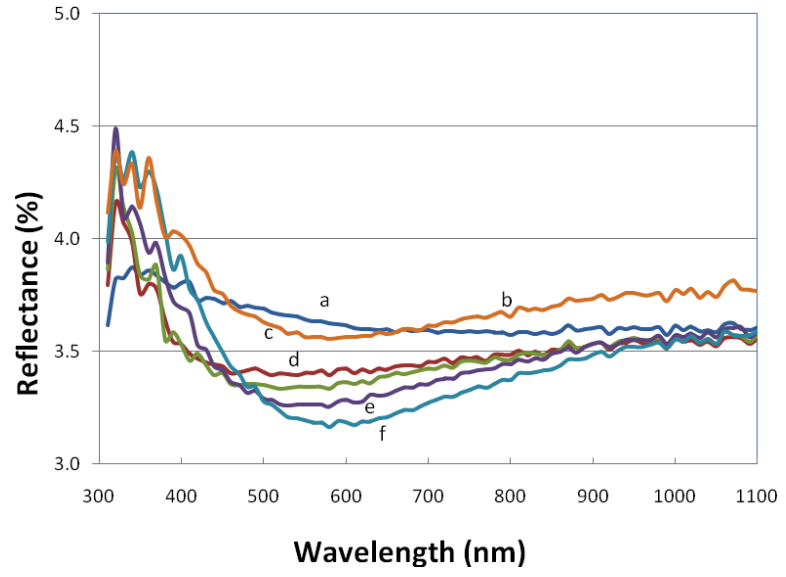

Figure 3 Reflectance of borosilicate glass implanted with $\mathrm{Ar}$ at $\mathbf{5 0} \mathrm{keV}$. Implant dose: (a) no implant; (b) $5 \times 10^{16} \mathrm{~cm}^{-2}$; (c) $5 \times 10^{15} \mathrm{~cm}^{-2}$; (d) $1 \times 10^{16} \mathrm{~cm}^{-2}$; (e) $2 \times 10^{16} \mathrm{~cm}^{-2}$; (f) $3 \times 10^{16} \mathrm{~cm}^{-2}$. 


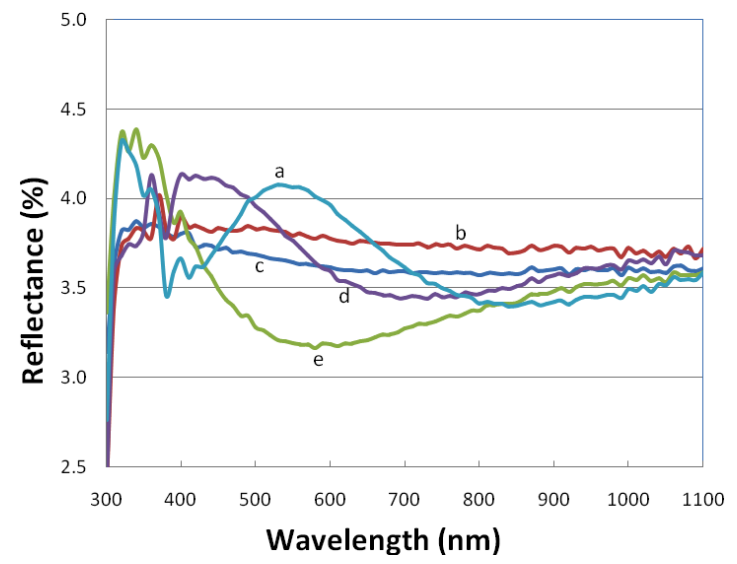

Figure 4 Reflectance of borosilicate glass implanted with Ar to a dose of $3 \times 10^{16} \mathrm{~cm}^{-2}$. Energy: (a) $105 \mathrm{keV}$; (b) $22 \mathrm{keV}$; (c) no implant; (d) $75 \mathrm{keV}$; and (e) $50 \mathrm{keV}$.

\section{COMPOSITIONAL DATA}

One proposed explanation for the change in index of refraction in soda lime glass is the rearrangement of the $\mathrm{Na}$ [3]. We have verified that the $\mathrm{Na}$ concentration has been modified by obtaining SIMS analysis ( Evans Analytical Lab) on two samples of the soda-lime glass. Fig. 5 shows the analysis of the sample implanted with $\mathrm{Ar}$ at $50 \mathrm{keV}$ and $3 \times 10^{16} \mathrm{~cm}^{-2}$, and Fig. 6 shows the same dose implanted at $105 \mathrm{keV}$. This is consistent with findings in the literature of the 1980's; however, we believe that the change in $\mathrm{Na}$ depth profile is not adequate to explain the change in index of refraction. We have used a model proposed by Fantone [6] to estimate the index of refraction as a function of composition, and to determine the change occurring from $\mathrm{Na}$ depletion. Using Fantone's method, we find that even if the $\mathrm{Na}$ were to be removed from the glass completely, it would not change the index of refraction sufficiently to explain our results.

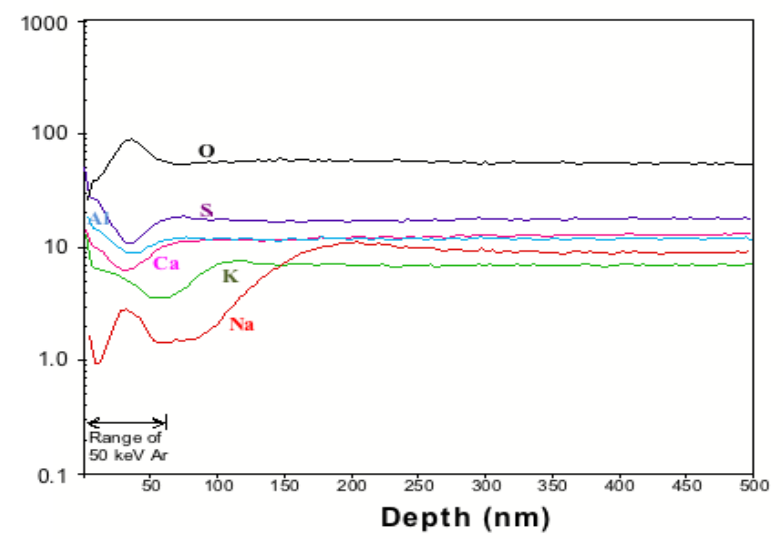

Figure 5 SIMS of low-Fe soda-lime glass implanted with $\mathrm{Ar}$ at $50 \mathrm{keV}, 3 \times 10^{16} \mathrm{~cm}^{-2}$.

Two alternate explanations are possible. The first is that the Ar implant breaks Si-O bonds in sufficient number in the soda-lime glass to cause a change in the dielectric constant. If this is the case, the change in index of refraction may be reversible upon annealing. The second alternate explanation is that the Ar implant forms micro-bubbles $[7,8]$ within the soda-lime glass; these bubbles reduce the density and therefore the dielectric constant of the glass. Such bubbles are observed using TEM $[7,8]$. Borosilicate glass generally has a higher softening temperature, indicating perhaps a more tightly bound system that would be less susceptible to bubble formation or disruption of atomic bonds. Work is in progress to determine the mechanisms at work in these materials.

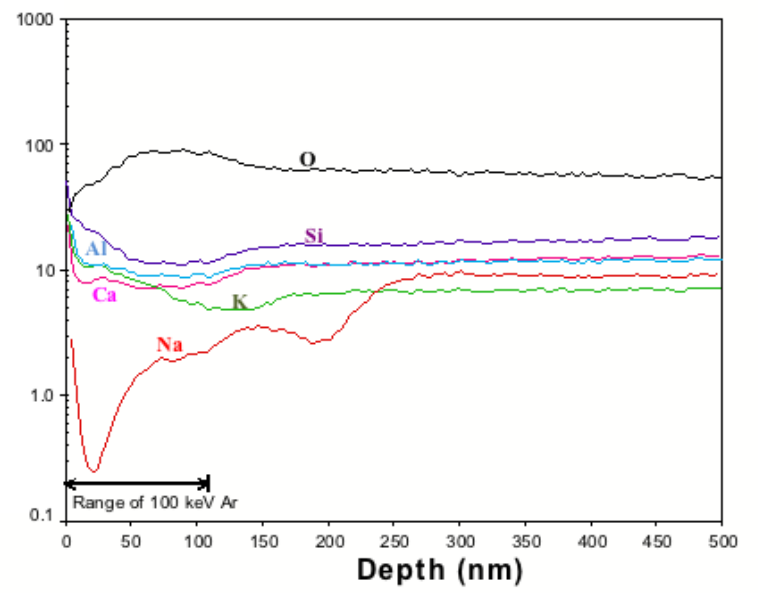

Figure 6 SIMS of low-Fe soda-lime glass implanted with Ar at $105 \mathrm{keV}, 3 \times 10^{16} \mathrm{~cm}^{-2}$.

\section{COMPARISON TO MgF 2}

Fig. 7 compares a calculation of an optimal $\mathrm{MgF}_{2}$ AR coating on glass compared to measured reflectance from $50 \mathrm{keV} \mathrm{Ar}$ ion implantation into Optiwhite glass. The solar weighted reflectance of the $\mathrm{MgF}_{2}$ layer is $1.9 \%$, and is not quite as good as the Ar-implanted layer.

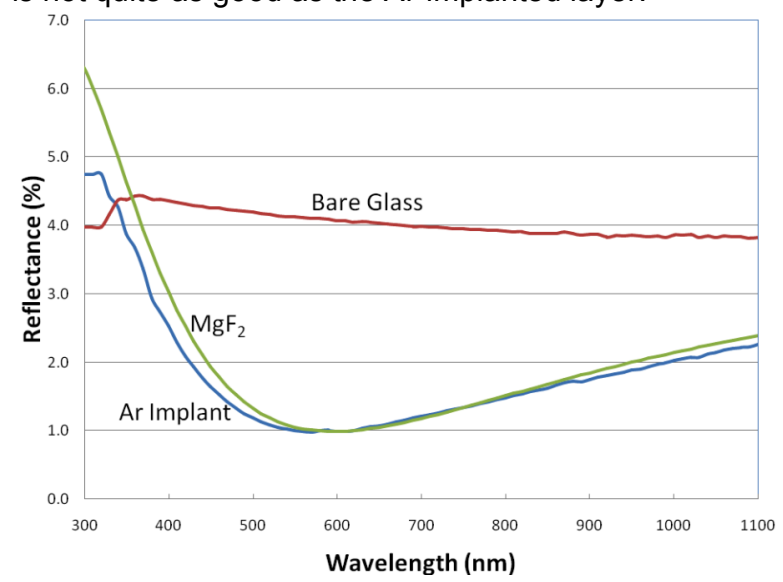

Figure 7 Calculated reflectance of an optimized $\mathrm{MgF}_{2}$ coating compared to measured reflectance of an Arimplanted layer. 
Note that the $\mathrm{MgF}_{2}$ curve in Fig. 7 is calculated, not measured. This illustrates that to a good approximation the Ar-implanted layer can be modeled as a single layer with an index of refraction similar to $\mathrm{MgF}_{2}$. A two-layer model can provide a nearly exact fit.

\section{CONCLUSIONS}

We have confirmed that ion implantation of $\mathrm{Ar}$ can reduce the reflectance of low-Fe soda-lime glass used in solar modules, and can produce a better result than is obtainable with a conventional $\mathrm{MgF}_{2}$ antireflection coating. We have not been able to produce as strong an effect in borosilicate glass. Although we have shown that the $\mathrm{Na}$ is rearranged in the soda-lime glass, we do not believe that the $\mathrm{Na}$ can account for the change in index of refraction that we observe. Further work is in progress to reduce the index of refraction further to obtain lower solar-weighted reflectance, and to understand better the underlying mechanisms.

\section{ACKNOWLEDGEMENTS}

This work was supported in part by the American Recovery and Reinvestment Act through Department of Energy contract DE-EE0000590. The authors are grateful to Richard White and Morgan Evans for supervising the ion implantation, and to S. Fantone for helpful discussions.

\section{REFERENCES}

[1] V. Chinellatov, V. Gottardi, S. Lo Russo, P. Mazzoldi, F. Nicoleti, and P. Polato, "Optical, Chemical and Mechanical Modifications Induced by Ion Implantation on Glass Surfaces," Radiation Effects, 65 p. 31 (Gordon and Breach Science Publishers, Inc., 1982), Presented at the First International Conference on Radiation Effects In Insulators, Arco, Lago di Garda, 1981.

[2] A. A. Deshkovskaya, "Ion Implantation in Glasses and Concomitant Effects," Radiation Effects, 103, p. 149 (1987).

[3] P. Polato, P. Mazzoldi, and A. B. Boscoletto, "Characterization by Nuclear and Spectrophotometric Analysis of Near-surface Modifications of Glass Implanted with Heavy lons," J. Am. Ceram. Soc., 70, p. 775 (1987).

[4] F. Geotti-Bianchini, P. Polato, S. Lo Russo, and P. Mazzoldi, "Antireflective Effects on a Soda-Lime Glass Induced by $\mathrm{Ar}^{+}$Implantation," J. Am. Ceram. 67, p. 39 (1984).

[5] P. D. Townsend, "Optical effects of ion implantation," Rep. Prog. Phys. 50 (1987) 501-558.

[6] S. Fantone, "Refractive index and spectral models for gradient-index materials," Applied Optics Vol. 22, p. 432 (1983).
[7] G. Battaglin, G. W. Arnold, G. Mattei, P. Mazzoldi, and J-C. Dran, "Structural modifications in ion-implanted silicate glasses," J. Appl. Phys. 85, p. 8040 (1999).

[8] G. W Arnold, G. Battaglin, G. Mattei, P. Mazzoldi, and S. Zandolin, "Implantation-induced structural changes and hydration in silicate glasses," Nuclear Instruments and Methods in Physics Research B 166-167 (2000) 440-444. 